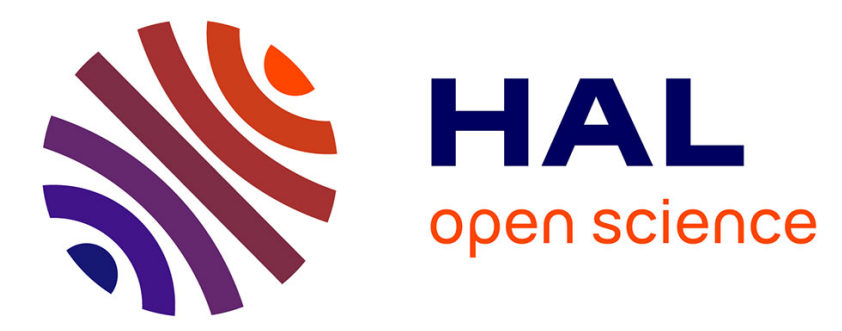

\title{
Addressing the Challenges of Inquiry-Based Learning Through Technology and Curriculum Design
}

Daniel C. Edelson, Douglas N. Gordin, Roy D. Pea

\section{To cite this version:}

Daniel C. Edelson, Douglas N. Gordin, Roy D. Pea. Addressing the Challenges of Inquiry-Based Learning Through Technology and Curriculum Design. The Journal of the Learning Sciences, 1999, 8(3-4), pp.391-450. hal-00190609

\section{HAL Id: hal-00190609 \\ https://telearn.archives-ouvertes.fr/hal-00190609}

Submitted on 23 Nov 2007

HAL is a multi-disciplinary open access archive for the deposit and dissemination of scientific research documents, whether they are published or not. The documents may come from teaching and research institutions in France or abroad, or from public or private research centers.
L'archive ouverte pluridisciplinaire HAL, est destinée au dépôt et à la diffusion de documents scientifiques de niveau recherche, publiés ou non, émanant des établissements d'enseignement et de recherche français ou étrangers, des laboratoires publics ou privés. 


\title{
Addressing the Challenges of Inquiry-Based Learning Through Technology and Curriculum Design
}

\author{
Daniel C. Edelson \\ Institute for the Learning Sciences and School of Education and \\ Social Policy \\ Northwestern University \\ Douglas N. Gordin and Roy D. Pea \\ Center for Technology in Learning \\ SRI International \\ Menlo Park, $C A$
}

Inquiry experiences can provide valuable opportunities for students to improve their understanding of both science content and scientific practices. However, the implementation of inquiry learning in classrooms presents a number of significant challenges. We have been exploring these challenges through a program of research on the use of scientific visualization technologies to support inquiry-based learning in the geosciences. In this article, we describe 5 significant challenges to implementing inquiry-based learning and present strategies for addressing them through the design of technology and curriculum. We present a design history covering 4 generations of software and curriculum to show how these challenges arise in classrooms and how the design strategies respond to them.

Students at all grade levels and in every domain of science should have the opportunity to use scientific inquiry and develop the ability to think and act in ways associated with inquiry. (National Science Education Standards, National Research Council [NRC], 1996, p. 105) 
Recent years have seen a growing call for inquiry to play an important role in science education (e.g., American Association for the Advancement of Science [AAAS], 1994; Blumenfeld et al., 1991; Linn, diSessa, Pea, \& Songer, 1994; NRC, 1996). This call for inquiry-based learning is based on the recognition that science is essentially a question-driven, open-ended process and that students must have personal experience with scientific inquiry to understand this fundamental aspect of science (Linn, Songer, \& Eylon, 1996; NRC, 1996, Project 2061). Furthermore, inquiry activities provide a valuable context for learners to acquire, clarify, and apply an understanding of science concepts. At the same time, computer technologies are receiving increased attention from the science education community because of excitement about their potential to support new forms of inquiry. These two reform trends are coming together in the form of numerous projects to create designs for technology-supported, inquiry-based science learning. For example, a large number of educational research and development projects are currently exploring the use of computers and networks to collect, exchange, and analyze scientific data. In the earth sciences alone, scores of educational projects have been initiated in the last decade to provide data and analysis tools to the educational community. Other projects engage learners in the collection and exchange of scientific data. Many of these projects in the United States are the direct result of National Aeronautics and Space Administration (NASA) and National Science Foundation funding programs designed to facilitate synergies between the scientific research and education communities. The goal of this article is to address the needs of designers of educational experiences like these.

Over the last 6 years, the authors have been engaged in the investigation of technology-supported inquiry learning (TSIL) through the design, implementation, and evaluation of scientific visualization tools for learners. Our goal has been to understand the opportunities and obstacles presented by scientific visualization as a technology to support inquiry-based learning. In the pursuit of this objective, we have developed a series of scientific visualization environments and inquiry-based curricula and have studied their use in both laboratory and public school classroom settings. In the course of this research, we have confronted a number of significant challenges to the implementation of inquiry-based learning and explored design strategies for responding to them. In this article, we discuss these challenges and strategies in the context of a design history covering four generations of software and curriculum. We begin with a discussion of the opportunities for learning provided by TSIL in general and how they apply to the specific domain of climate science and the specific technologies of scientific visualization. We then present a summary of the challenges for implementing inquiry learning that this design history addresses, followed by the design history itself. Following the history, we highlight the design strategies we pursued and describe how they address the challenges to inquiry-based learning. We conclude with a brief discussion of the next steps for design and evaluation in this research. 


\section{THE POTENTIAL OF TSIL}

Inquiry, the pursuit of open questions, is fundamental to the practice of science. Inquiry-based science learning is based on the idea that science learning should be authentic to science practice, an idea advocated by Dewey (1964a, 1964b). Modern support for inquiry-based learning comes from research in cognitive science that provides evidence for the importance of activity and authentic contexts for learning (e.g., Greeno, Collins, \& Resnick, 1996). Authentic activities provide learners with the motivation to acquire new knowledge, a perspective for incorporating new knowledge into their existing knowledge, and an opportunity to apply their knowledge. In contrast to the passive reception of knowledge associated with conventional science learning, inquiry is active. As an authentic scientific practice, inquiry also provides a valuable context for science learning.

In this section, we provide a brief rationale for incorporating inquiry into science education and for using technology to support inquiry-based learning. To do so, we highlight the opportunities for learning provided by inquiry and the opportunities to support inquiry-based learning provided by computer technologies. We discuss these opportunities both in general and in the specific case of climatology and scientific visualization that we have explored in our research.

\section{Opportunities for Learning}

Scientists' knowledge of scientific concepts, understanding of scientific tools and media, and inquiry skills are inextricably intertwined. Our goal in attempting to implement inquiry-based science learning is to help students develop this same sort of integrated understanding. Participation in inquiry can provide students with the opportunity to achieve three interrelated learning objectives: the development of general inquiry abilities, the acquisition of specific investigation skills, and the understanding of science concepts and principles.

The first opportunity for learning provided by inquiry is the opportunity to develop general inquiry abilities. In its prototypic form, inquiry-based science learning involves the pursuit of open-ended questions and is driven by questions generated by learners (Blumenfeld et al., 1991; Linn et al., 1996; Welch, Klopfer, Aikenhead, \& Robinson, 1981). In practice, posing researchable questions and pursuing them through open-ended investigations are abilities that must be learned. General inquiry abilities include posing and refining research questions, planning and managing an investigation, and analyzing and communicating results. Inquiry activities provide the opportunity to develop and exercise these general inquiry abilities.

Inquiry also provides the opportunity to acquire specific investigation skills. Different disciplines of science use different methods of investigation and differ- 
ent standards of evidence. Some forms of inquiry that have been explored by educational researchers include controlled experimentation (Schauble, Glaser, Duschl, Schulze, \& John, 1995), modeling (Jackson, Stratford, Krajcik, \& Soloway, 1996; Penner, Giles, Lehrer, \& Schauble, 1997; Resnick, 1994; Wilensky \& Resnick, 1999), synthesis of primary sources (Linn, Bell, \& Hsi, 1998; Wallace et al., 1998), and exploration of quantitative data (Hancock, Kaput, \& Goldsmith, 1992; Tabak, Smith, Sandoval, \& Reiser, 1996). Each of these forms of investigation has its own specific procedures and skills. Within these forms, there are even further differences between scientific disciplines. For instance, the design of controlled experiments in chemistry is very different from the design of controlled experiments in psychology. The inquiry-based approach to science learning provides learners with the opportunity to learn these scientific practices by engaging in them themselves.

The third opportunity for learning provided by inquiry is the chance to develop an improved understanding of science concepts. Inquiry activities can contribute to this knowledge acquisition process by providing a meaningful context for learning. However, it is important to distinguish inquiry learning from discovery learning (Bruner, 1961; de Jong \& van Joolingen, 1998). In our conception of learning from inquiry, students can discover scientific principles through their inquiry activities, but discovery is not the only mechanism for learning from inquiry. Inquiry can contribute to the development of science content understanding in all of the following ways:

Problematize (Hiebert et al., 1996). Inquiry activities can lead learners to confront the boundaries of their knowledge or recognize gaps in that knowledge. The limits of one's knowledge are often revealed by the failure of an expectation about a particular situation (Schank, 1999) leading to curiosity. The curiosity elicited by such problematic situations creates a focused motivation to learn (Berlyne, 1966).

Demand. Successfully completing a scientific investigation requires science content knowledge. The design of an inquiry activity can, therefore, place a demand for knowledge on the part of a learner that will require him or her to acquire it to complete the investigation successfully.

Discover and refine. By providing learners with the opportunity to pursue answers to questions, inquiry activities can enable learners to uncover new scientific principles and refine their preexisting understanding of scientific principles in the answers that they construct.

Apply. Inquiry activities can give learners the opportunity to apply their scientific understanding in the pursuit of research questions. The need to apply scientific knowledge can require a learner to reorganize and re-index it in ways that will support its future use. The application of existing knowledge can also reinforce it and enrich its connections to other knowledge. 


\section{Technological Support for Inquiry-Based Learning}

Computing and networking technologies offer dramatic, new opportunities to support inquiry-based learning. For instance, in their analysis of technology as a support for project-based science learning, Blumenfeld et al. (1991) identified six contributions that technology can make to the learning process:

- Enhancing interest and motivation.

- Providing access to information.

- Allowing active, manipulable representations.

- Structuring the process with tactical and strategic support.

- Diagnosing and correcting errors.

- Managing complexity and aiding production.

All of the fundamental properties of computing technologies offer benefits for inquiry-based learning - the ability to store and manipulate large quantities of information, the ability to present and permit interaction with information in a variety of visual and audio formats, the ability to perform complex computations, the support for communication and expression, and the ability to respond rapidly and individually to users. With regard to the inquiry process in particular, a variety of promising technologies have been developed for learners, including tools for modeling phenomena and processes from the real world (e.g., Model-It, Jackson et al., 1996; STELLA, Mandinach \& Cline, 1996; ThinkerTools, White, 1993), visualizing and analyzing quantitative data (e.g., TableTop, Hancock et al., 1992; WW2010, Plutchak et al., 1998; GLOBE, Rock, Blackwell, Miller, \& Hardison, 1997; Blue-Skies, Samson et al., 1994), exchanging data and ideas across distances (GLOBE, Rock et al., 1997; Kids As Global Scientists, Songer, 1995), structuring and supporting discussion (e.g., CoVis Collaboratory Notebook, Edelson, Pea, \& Gomez, 1996a; Gomez \& O'Neill, 1994; CaMILE, Guzdial, Turns, Rappin, \& Carlson, 1995; SpeakEasy, Hoadley, Hsi, \& Berman, 1995; CSILE, Scardamalia \& Bereiter, 1994), and providing access to information in the form of digital collections and libraries (e.g., Knowledge-Integration Environment, Linn et al., 1998; ARTEMIS, Wallace et al., 1997). In our approach to inquiry-based learning, computer technologies are used to provide investigation tools, knowledge resources, and record-keeping tools.

\section{An Example: Climatology and Scientific Visualization}

The field of climate science and the technologies of scientific visualization both provide rich opportunities for inquiry-based learning. In combination, they provide 
opportunities to exploit technology as a support for inquiry to achieve the three categories of learning objectives described previously.

Climatology. The science of climate is an important area for study because, like the other geosciences, it integrates the sciences of physics, chemistry, biology, and geography. It provides an opportunity to apply a systems approach to science learning that is increasingly practiced in the earth sciences (Ireton, Manduca, \& Mogck, 1996; NASA Advisory Council, 1988). Climatology also provides an opportunity for students to develop an understanding of processes on scales ranging from local to global. Climate topics, including the cause of the seasons, energy transfer from sun to earth, and the role of sunlight in photosynthesis, are included in the secondary science education content standards for earth science published by both the American Association for the Advancement of Science (AAAS, 1994) and the National Research Council (NRC, 1996).

Because the study of large-scale atmospheric processes does not permit experimentation, climatology has historically been an observational science requiring the collection and analysis of data (Frodeman, 1995), although it increasingly involves the generation of data through computational models. The availability of large-scale data collection mechanisms, including remote-sensing satellites and networked data collection stations, has led to an explosion of data available to support scientific investigation of climate (NASA, 1998). The techniques of two-dimensional geographic visualization and data analysis that we investigate in this research have played an important role in the practice of climatology in the years since these large databases and analysis tools have been available. The availability of the data and the impact of visualization technologies on the practice of science in this field provided the initial inspiration for this research.

Scientific visualization. The term scientific visualization covers a class of techniques for rendering data that take advantage of the computer's powerful capabilities for graphical and animated display (McCormick, DeFanti, \& Brown, 1987). Scientific visualization techniques are used to display data visually through the systematic variation of color, shape, orientation, and position. The techniques of scientific visualization have had an enormous impact on many fields of science because they exploit the ability of the human visual system to identify patterns in visual imagery, where previously scientists could only search for such patterns through complex, analytical processing. For example, atmospheric scientists have made great leaps in their understanding of processes as small as individual thunderstorms and as large as global climate change by collecting and modeling enormous quantities of data and rendering them in visual displays (Kaufmann \& Smarr, 1993). Scientists use visualization not just for inquiry but also for communication, to report 
findings, and to convince others. As a glance at virtually any journal in the geosciences reveals, scientific visualizations now play an important role in communication within the scientific community.

Previously, we have argued that scientific visualization offers great promise as a support for science learning (Gordin \& Pea, 1995). The same properties that have made visualization a powerful technology for scientific discovery by scientists - the ability to render complex data for visual interpretation-make it a potentially powerful tool for science learning by students. Furthermore, as a technology for investigation and a medium for communication, scientific visualization can provide students with a means to participate in the practice of science, thereby benefiting from the inquiry-based learning that is increasingly being recognized as a critical element of science education. Finally, as a set of visual representations, scientific visualization formats are likely to take a place alongside charts and graphs as representations that students must master to become competent decisionmakers in a world that is increasingly influenced by science and technology.

In our research, we have focused primarily on the use of scientific visualization for the analysis of large collections of quantitative data created by the scientific community. The form of visualization that we have focused on is the display of rectangular arrays of geographic data that use colors to represent ranges of numerical or categorical values. This "color map" geographic representation (Figure 1) is widely used in the atmospheric sciences community and appears increasingly in popular media, such as the daily weather maps in USA Today. The research reported here has taken place concurrently with a number of efforts exploring the use of visualization and data analysis in a variety of disciplines (e.g., Asbell-Clarke \& Barclay, 1996; Barstow \& Berenfeld, 1996; Greenberg, Kolvoord, Magisos, Strom, \& Croft, 1993; Rock et al., 1997).

Leaming objectives for climatology and inquiry through visualization. The combination of visualization and climatology has provided us with a set of integrated learning objectives covering both inquiry and science content. At the level of general inquiry skills the objective that has guided our design efforts is to help learners develop the skills of formulating and refining researchable questions, planning and conducting coherent investigations, and reporting and applying results. In the specific domain of visualization and analysis of quantitative data, our objectives for students include the ability to use the techniques of visualization to identify and quantify patterns and anomalies in data, to employ arithmetic and statistical techniques to explore the relations between varying quantities, and to present results and support arguments. In the content area of atmospheric science, our objective is to help learners develop an integrated understanding of the radiative energy transfer processes of emission, absorption, and reflection and how those physical 


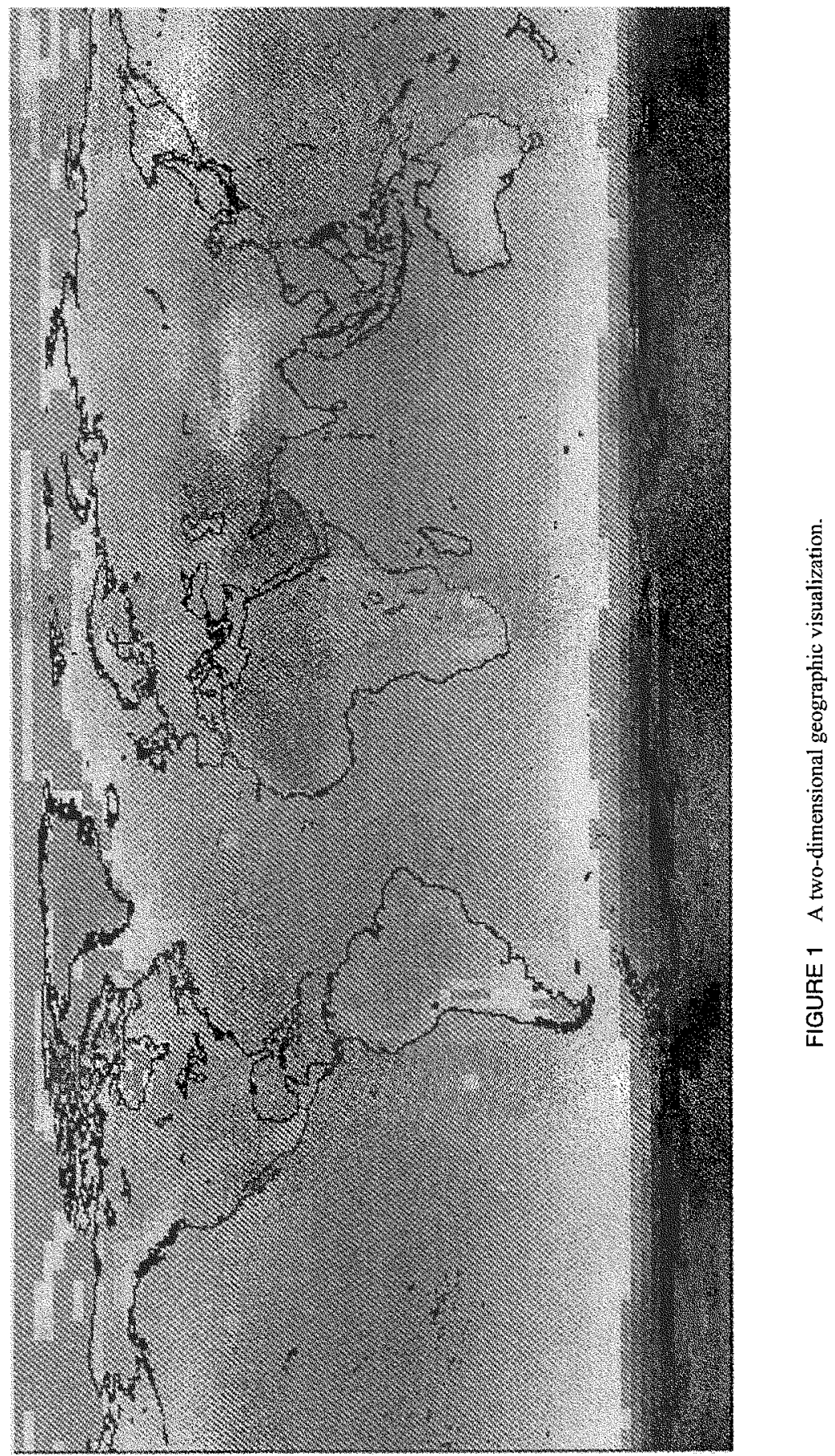


processes interact with the physical geography of the earth and atmospheric chemistry to determine climatic conditions on Earth.

\section{THE CHALLENGES OF IMPLEMENTING INQUIRY-BASED LEARNING}

Although inquiry offers compelling opportunities for science learning, there are many challenges to the successful implementation of inquiry-based learning. For example, researchers have documented that children have difficulties conducting systematic scientific investigations (e.g., Kraijcik et al., 1998; Schauble et al., 1995). Data gathering, analysis, interpretation, and communication are all challenging tasks that are made more difficult by the need for content-area knowledge. Although we entered this design process with some specific ideas of how technology could be used to address the challenges of inquiry-based learning, we found that these challenges appeared in many forms and that responding to them effectively almost always required the use of both technological and curricular design strategies. In this article, we focus on five of the most significant challenges to the successful implementation of inquiry-based learning. The experiences described in the following sections demonstrate that the failure to address any of these challenges successfully can prevent students from successfully engaging in meaningful investigations and therefore undermine learning. The five challenges are as follows:

1. Motivation. For students to engage in inquiry in a way that can contribute to meaningful learning they must be sufficiently motivated. The challenging and extended nature of inquiry requires a higher level of motivation on the part of learners than is demanded by most traditional educational activities. To foster learning, that motivation must be the result of interest in the investigation, its results, and their implications. When students are not sufficiently motivated or are not motivated by legitimate interest, they either fail to participate in inquiry activities or they participate in them in a disengaged manner that does not support learning. Motivation is recognized by Soloway, Guzdial, and Hay (1994) as one of three primary challenges for Learner-Centered Design.

2. Accessibility of investigation techniques. For students to engage in inquiry, they must know how to perform the tasks that their investigation requires, they must understand the goals of these practices, and they must be able to interpret their results. Scientific investigation techniques such as data collection and analysis can be complicated and typically require a level of precision and care that are not required of students in their everyday experiences. If students are not able to master these techniques, then they cannot conduct investigations that yield meaningful results. The need for tools to be accessible to learners across the full diver- 
sity of abilities and prior experiences is another challenge of Learner-Centered Design raised by Soloway et al. (1994).

3. Background knowledge. The formulation of research questions, the development of a research plan, and the collection, analysis, and interpretation of data all require science content knowledge. In designing inquiry-based learning, the challenge is providing opportunities for learners to both develop and apply that scientific understanding. If students lack this knowledge and the opportunity to develop it, then they will be unable to complete meaningful investigations.

4. Management of extended activities. To achieve the ultimate goal of open-ended inquiry, students must be able to organize and manage complex, extended activities. A scientific investigation requires planning and coordination of activity and the management of resources and work products. Students are not typically asked to manage extended complex processes as part of traditional educational activities. If they are unable to organize their work and manage an extended process, students cannot engage in open-ended inquiry or achieve the potential of inquiry-based learning.

5. The practical constraints of the learning context. The technologies and activities of inquiry-based learning must fit within the practical constraints of the learning environment, such as the restrictions imposed by available resources and fixed schedules. Although this challenge may not have the same theoretical importance as the other four for advancing our understanding of the learning sciences, it has enormous practical implications for design. A failure to work within the available technology or fit within the existing schedule in a school will doom a design to failure. Therefore, meeting the constraints of the environment is a critical consideration in design that must be considered alongside learning needs in the design of curriculum and technology.

In the sections that follow we present the history of our efforts to address these challenges in the area of climate science. In the course of this process, we employed a variety of technological and curricular design strategies, some drawn from the work of others, some novel. These strategies include

Meaningful problems. A meaningful problem is one that has implications that matter to students. As many advocates of project- and inquiry-based science have argued (e.g., Barron et al., 1998; Blumenfeld et al., 1991), a meaningful problem can be used to establish a motivating context for scientific inquiry.

Staging activities. Staging activities are sequences of structured investigations that introduce learners to investigation techniques, help to develop background knowledge, and establish a motivating context. They can be used to set the stage for open-ended inquiry activities. The progression from staging activities to open-ended inquiry resembles the progression from problem-based to project-based learning described by Barron et al. (1998). 
Bridging activities. Bridging activities are designed to bridge the gap between the practices of students and scientists. Bridging activities employ practices that are familiar to students as a means of introducing unfamiliar scientific practices.

Supportive user-interfaces. A supportive user-interface provides scaffolding for learners by embedding the tacit knowledge of an expert in the user-interface. Supportive user-interfaces can make investigation tools more accessible to learners. Our approach to supportive interfaces resembles the use of scaffolds in Learner-Centered Design (Jackson et al., 1996; Soloway at al., 1994).

Embedded information sources. An embedded information source is a library of resources that is linked directly to an investigation tool. They can provide learners with just-in-time access to information that can provide the background knowledge necessary to complete an investigation. The use of information sources in this way resembles the use of Ask Systems (Ferguson, Bareiss, Birnbaum, \& Osgood, 1992) in the Goal-Based Scenario architecture (Schank, Fano, Bell, \& Jona, 1993/1994).

Record-keeping tools. Record-keeping tools allow learners to record the process and intermediate products of an extended activity. They can be used to support the management and organization of inquiry activities.

In the design history presented below, we describe the selection and use of each of these strategies in the course of the iterative design process. Following the design history, we elaborate on these strategies and their value for addressing the challenges of inquiry-based learning.

\section{INTRODUCTION TO THE DESIGN HISTORY}

Since we started this research in 1992, we have developed four generations of scientific visualization environments for archival climate data.' This research began under the Learning through Collaborative Visualization (CoVis) Project (Pea, 1993) and has continued under the Supportive Scientific Visualization Environments for Education Project and the Center for Learning Technologies in Urban Schools (LeTUS). All are National Science Foundation-sponsored, educational technology research efforts targeted at the reform of science education at the middle and high school levels. This particular research on scientific visualization for learners is one component of a broad effort to provide authentic science experiences for learners (Edelson et al., 1996b; Pea, 1993).

\footnotetext{
'We have also developed visualization environments for the investigation of real-time weather data. That work, in collaboration with researchers in the Department of Atmospheric Sciences at the University of Illinois at Urbana-Champaign, is described elsewhere (Fishman \& D'Amico, 1994; Plutchak et al., 1998).
} 
Our adaptation of scientific visualization technologies for learners began with an examination of the way that researchers use scientific visualization in their work and an evaluation of the potential for scientific visualization as a tool to support learners (D'Amico et al., 1994; Gordin \& Pea, 1995). Our earliest design efforts focused primarily on technological issues, such as designing user-interfaces to scientists' tools that provided scaffolds to enable learners to participate in the practices of scientists. These efforts were guided by the principles of Learner-Centered Design (Soloway et al., 1994). As we recognized the limits of technology to fully address the challenges of inquiry-based learning, we broadened our efforts to include curriculum design.

The design and evaluation described here were conducted using an informal, collaborative approach. Design was done by teams at Northwestern University that included faculty in education and computer science, graduate students, professional programmers, and practicing teachers. Input and feedback were sought frequently from content area scientists. Use of the software and curriculum were observed both in classroom and laboratory settings. Records of these uses were collected through a combination of direct observation by the research team, videotaping, interviews and journals of teachers and students, and unsolicited feedback from teachers. With a few exceptions, the evaluation was informal because we were involved in a rapid cycle of iterative design and implementation. The issues discussed here were all revealed by clearly identifiable problems in classroom experiences, such as the failure of learners to engage in inquiry or their inability to complete an inquiry successfully with the time and resources available. As we begin to see evidence that these obvious problems have been resolved, we are shifting our efforts increasingly from identifying problems to characterizing impacts. We are therefore launching some more formal evaluation efforts, which we discuss in the final section of this article.

Although the following discussion focuses primarily on the issues that were raised as a result of our observations of students in classrooms, there were many other influences on the design process. These influences included (a) scientific researchers, through observation of their practices and advice they offered; (b) educational researchers, through writings, examples of software and curriculum, and conversation; and (c) teachers, through observation of their practice and advice they offered.

In the following sections, we describe the four generations of visualization environments and the curriculum we developed to accompany them. The four visualization tools are the Climate Visualizer, Radiation-Budget Visualizer, Greenhouse Effect Visualizer, and WorldWatcher. Throughout the design history, certain basic characteristics of the visualization tools have remained the same. They all display data in the same two-dimensional, gridded color map format, and they were all designed to provide an integrated suite of data and tools. For each design, we summarize the considerations that were most important in the design, data, architecture, 
and features of the software, the curriculum that was designed to go with the software, and its use. We then discuss how the design attempted to address the challenges of fostering inquiry-based learning and the issues that were raised by the use of the design by teachers and student.

\section{THE CLIMATE VISUALIZER}

The Climate Visualizer (Gordin, Polman, \& Pea, 1994) was the first visualization environment we developed. It was first distributed to teachers participating in the CoVis Project in the fall of 1993. Its design was heavily influenced by the research and teaching practices of our collaborating climatologist. In fact, we conceived of the Climate Visualizer as a direct adaptation of a scientist's tool for use by learners.

The goal of the Climate Visualizer was to put the powerful features of scientists' visualization environments into the hands of high school students. Because of the complexity of their user-interfaces and the challenges they posed to interpreting visualizations, we concluded that the actual tools used by scientists were inaccessible to mainstream high school students. Therefore, the primary design goal of the Climate Visualizer was to respond to the challenge of making investigation techniques accessible to learners. At this stage in the design process, we viewed accessibility as a technological challenge, which we addressed by designing a supportive user-interface for the Climate Visualizer. This supportive interface provided significantly more structure and information in its user-interface than a comparable tool designed for scientists.

\section{Data Library}

The Climate Visualizer's data library contained basic weather data for the Northern Hemisphere above $20^{\circ}$ latitude, covering a period from the early 1960 s to the late 1980s. The data included measurements of temperature, wind speed and direction, and atmospheric pressure at several levels in the atmosphere, all recorded at 12-hr intervals. These data are used by researchers to investigate general climate patterns and specific large-scale weather events in the Northern Hemisphere.

\section{Software Architecture, Features, and Interface}

In contrast to the general-purpose visualization environments used by scientists, the Climate Visualizer's interface was customized to the data in its data library. The Climate Visualizer was implemented as a "front-end" to Transform, a powerful scientific visualization environment that is widely used in the research community. 
Users selected data to view in the Climate Visualizer by specifying a date, time of day, and one or more variables from a menu of available data. The data were then downloaded over the Internet from a server, rendered by the Transform visualization engine, and transferred to the Climate Visualizer for display. To enhance performance, data sets were cached on the local computer for future use once they had been downloaded.

Like the visualizers that succeeded it, the Climate Visualizer presented visualizations in the form of gridded, two-dimensional color maps in a rectangular projection (Figure 2). Temperature was displayed as the main color map, atmospheric pressure as contour overlays, and wind speed and direction as vector overlays. The Climate Visualizer provided users with the ability to customize their visualizations by varying the colors that were used to represent data values and by changing the numerical range of the color palette. The Climate Visualizer supported comparison of data sets by allowing users to view them simultaneously side by side or by subtracting them from each other.

\section{Curriculum Design}

We did not create any curriculum to accompany the Climate Visualizer initially. At the time we did not feel predesigned curricula were appropriate because we were hoping to foster an entirely student-driven form of inquiry-based learning in which students would generate and pursue their own research questions. We designed the Climate Visualizer with the expectation that the data and tools in the Climate Visualizer would lead students to pose questions and pursue them through open-ended investigations. To the extent that we engaged in curriculum design at all, that design consisted of recommending to teachers that they have their students explore the data in the Climate Visualizer in an open-ended fashion to identify interesting questions to investigate and then pursue those questions with the guidance of the teacher through open-ended inquiry.

\section{Use}

The Climate Visualizer was first used by students in a workshop led by CoVis teachers in the summer of 1993. In the 1993-1994 school year, it was used for a period of 2 weeks in the classes of one of the six teachers participating in the CoVis project at that time. It was used for a few days in the classes of two of the other teachers that year.

Issues Addressed by the Design

The Climate Visualizer was designed to address the challenge of making the visualization technologies used by scientists accessible to learners. One of the most sig- 


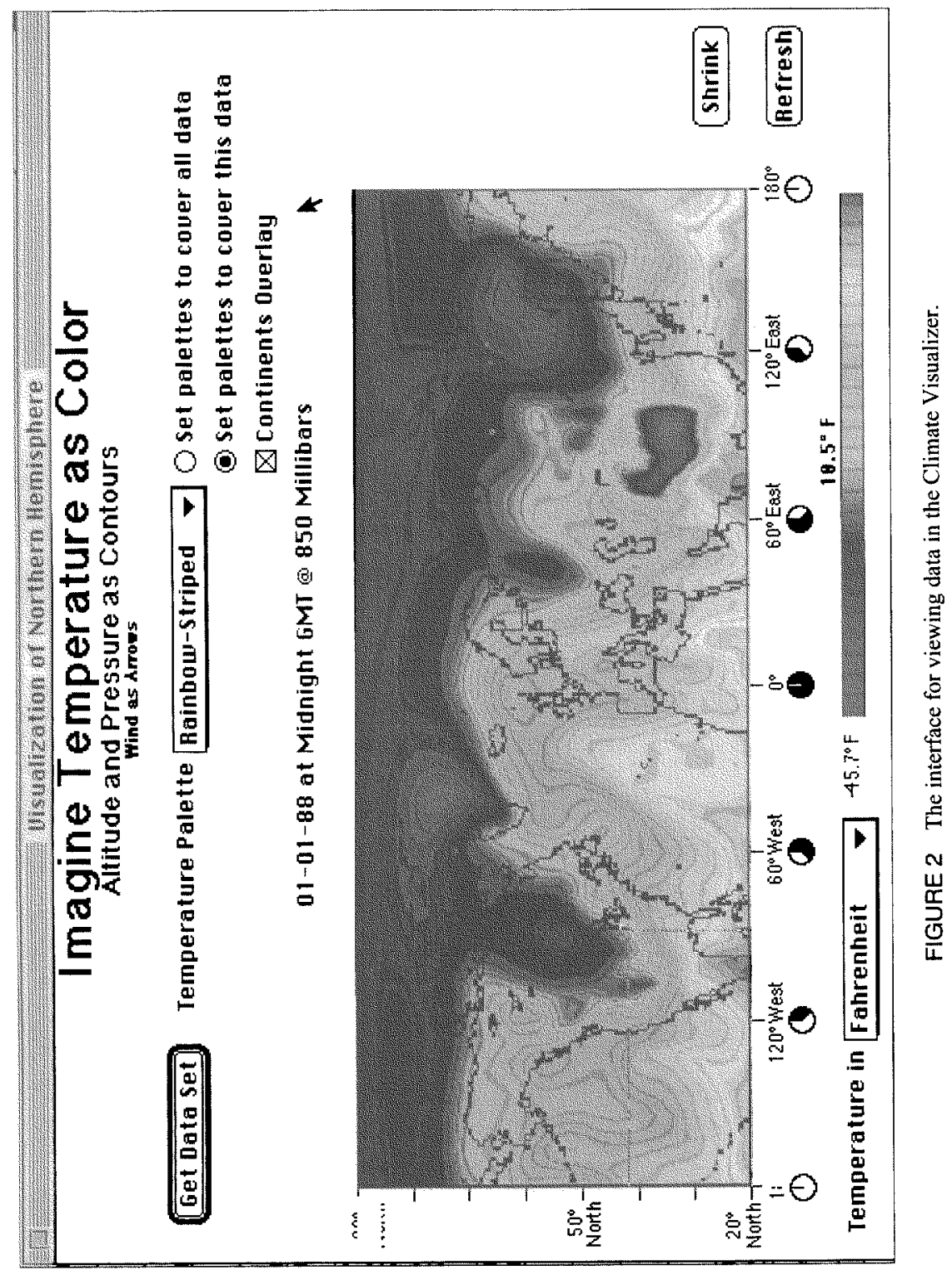


nificant obstacles to the use of scientists' tools by learners is the lack of contextual knowledge that they provide. Because scientists bring an extraordinary amount of tacit knowledge about geography, the data being displayed, and the phenomena that the data represent, they are able to work in a relatively information-poor environment. For example, Figure 3 shows a screen from Transform, the popular and extremely powerful two-dimensional visualization environment designed for researchers that we used as the visualization engine for the Climate and Radiation-Budget Visualizers. To a nonexpert, the visualization is almost completely uninterpretable. The variable being displayed is encoded in the file name that serves as the title for both windows. A careful reading of "T850_1_1_88_0Z" that appears in the title bar reveals to a researcher who is familiar with this data that he or she is viewing the average midnight Greenwich Mean Time for January 1988 at the 850 millibar equal-pressure surface in the atmosphere. The geographic range and scale of the displayed region are not identified, and the numbers that appear in the window at the side have no units or any indication of how their values map into colors in the visualization. Finally, the operations that are available to the user are all concealed in menus. As lacking in support as this interface is, expert researchers have no difficulty working with data and visualizations in this form because of the extensive knowledge that they bring to the task.

In contrast to the interface displayed in Figure 3, the supportive scientific visualization interface in the Climate Visualizer provided scaffolds for learners in the form of contextual information about geography (through latitude and longitude markings, as well as continent overlays), about units (through labels), and about the mapping of numerical values to colors (through a color palette display). The Climate Visualizer allowed users to specify the units in the display, so that students who were more familiar with Fahrenheit could interpret visualizations using values with which they were comfortable. The color palette display in the Climate Visualizer tracked the movement of the cursor and displayed the numerical value for the current cursor location over its corresponding color in the color bar. Finally, all of the operations that the user could perform were displayed as permanently visible buttons in the Climate Visualizer interface.

A second place that the Climate Visualizer provided support that was not available in general-purpose scientists' tools was in the interface for selecting the data to visualize. Comparable tools for scientists typically require users to identify data sets by specifying file names, which in most data libraries are abbreviated and obscure, as in the "T850_1_1_88_0Z" in Figure 3. In contrast, the Climate Visualizer allowed users to select data from the data library by choosing variable names, dates, and times from a menu of available options. This required that we customize the Climate Visualizer to the specific data in its library, which would compromise the generality that scientists rely on in their tools.

The third place that the Climate Visualizer provided additional support for learners was in the form of default settings for the display parameters. The Climate 
\& File Edit Image Numbers Templates Tables Windows

\begin{tabular}{|c|c|c|c|c|}
\hline \multicolumn{4}{|c|}{ T850_1_1_88_02:0 } & 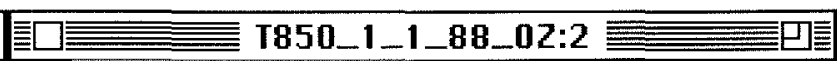 \\
\hline$-m$ & -124.0 & -120.0 & -116.0 㲅 & 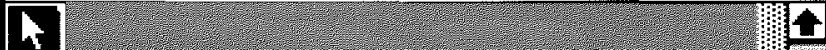 \\
\hline 72.0 & $-1.772 e+01$ & $-1.778 \mathrm{e}+01$ & $-1.744 \mathrm{e}+$ & \\
\hline 70.0 & $-1.396 e+01$ & $-1.365 e+01$ & $-1.315 e+$ & \\
\hline 68.0 & $-1.157 e+01$ & $-1.091 e+01$ & $-1.025 \mathrm{e}$ & \\
\hline 66.0 & $-1.002 e+01$ & $-8.903 e+00$ & $-8.395 e+$ & 然 \\
\hline 64.0 & $-7.560 e+00$ & $-5.650 \mathrm{e}+00$ & $-5.840 e+$ & 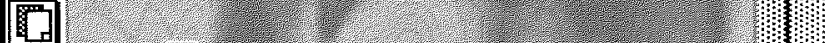 \\
\hline 62.0 & $-5.85010+100$ & $-2.11 \mathrm{~B} e+00$ & $-4.142 \mathrm{e}+$ & \\
\hline 60.0 & $-5.954 e+00$ & $-3.0400+00$ & $-4.451 \mathrm{E}$ & \\
\hline 58.0 & $-6.677 e+00$ & $-3.9400+00$ & $-6.537 t$ & \\
\hline 56.0 & $-8.423 E+00$ & $-7.758 \mathrm{e}+00$ & $-1.017 e+$ & \\
\hline 54.0 & $-1.162 e+01$ & $-1.313 e+01$ & $-1.973 e+$ & \\
\hline 52.0 & $-1.046 e+01$ & $-1.568 \mathrm{e}+101$ & $-1.528 \mathrm{e}+$ & \\
\hline 50.0 & $-7.574 e+00$ & $-1.3198+01$ & $-1.4850+$ & \\
\hline 48.0 & $-4.976 e+00$ & $-7.995 e+00$ & $-1.232 \mathrm{e}+$ & \\
\hline 46.0 & $-3 \cdot 399 e+00$ & $-3.047 e+00$ & $-8.368 \mathrm{e}+$ & \\
\hline 44.0 & $-2.810 e+00$ & $-2.406 e+00$ & $-6.893 e+$ & 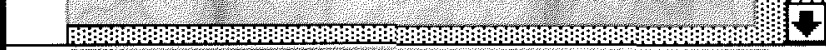 \\
\hline 42.0 & $-2.364 e+00$ & $-4.276 e+00$ & $-7.236 \mathrm{e}$ & W \\
\hline 40.0 & $-1.069 e+00$ & $-4.408 e+00$ & $-9.045 e$ & $\begin{array}{l}50.0: 62.0 \\
509-128.0:-\end{array}$ \\
\hline 38.0 & $9.719 e-02$ & $-3.001 e+00$ & $-7.949 e+\sqrt{3}$ & \\
\hline & & & का & 4 \\
\hline
\end{tabular}

3 FIGURE 3 A visualization of temperature data for the Northern Hemisphere displayed by Transform, a powerful, general-purpose visualization environment widely used by scientific researchers. 
Visualizer provided learners with access to a number of powerful operations for the analysis of data, such as the ability to customize the display of visualizations, sample data values for individual points in an image, select regions of interest, and coordinate the simultaneous interpretation of multiple data sets. As we began to work with these operations during the design process ourselves, we recognized that access to these powerful operations can be a double-edged sword. For example, the ability to modify the color palette means that with a simple change to one display parameter, a visualization can be transformed from a multicolored, highly patterned color map to a blank, monochromatic field. We learned that an important component of a scientist's expertise is knowing how to set display parameters so that a data set will display in a meaningful form. Without adequate support, a novice who does not yet understand the units or range of values in a data set can spend a great deal of time working with a visualization just to display it in a way that will allow him or her to begin to interpret it. To protect learners from undue frustration in the early stages of interpretation, we created a scaffold in the form of default display settings for data. For each variable in the data library, we established default display settings for the color scheme, its range, and the units displayed. For temperature, for example, the default color scheme was made up of five colors arranged in the order of the rainbow, and the default units were degrees Fahrenheit. Any time a user selected a data set to view, it was displayed using these defaults. The defaults served as a scaffold that enabled learners to begin to interpret visualizations without needing to set display parameters that they may not yet understand. However, the ability to customize the display of visualizations still allowed learners to progress to more sophisticated interpretations.

When we observed the Climate Visualizer's use in schools, we found that students at a wide range of ability levels were able to use its supportive interface to select data and to display and interpret visualizations. The first activity that many students did with the Climate Visualizer was to research the weather conditions on the day they were born. With little or no instruction, students were able to retrieve the data for the date they were born, locate the cell on the visualization covering their birthplace, and use the display to identify temperature. In each of these steps, students took advantage of the contextual information embedded in the user-interface. For example, the map overlay and latitude/longitude markings enabled students to locate the area they were interested in, and the readout that tracks the movement of the cursor enabled them to access the underlying data values. These steps would have been extremely difficult if not impossible using an information-poor interface like the one in Figure 3. Unfortunately, we had few opportunities to see whether the supportive interface made more sophisticated analyses of data more accessible because of other challenges discussed in the next section.

In addition to the issue of accessibility, our design for the Climate Visualizer also addressed the challenge that students face in managing extended activities in inquiry-based learning. Based on the advice of experienced inquiry-based science 
teachers and prior experience with Project INQUIRE (Hawkins \& Pea, 1987), we were concerned that students would have difficulty planning, organizing, and coordinating the inquiry process when they used the Climate Visualizer. Teachers with experience supervising open-ended projects told us that teaching students to manage open-ended activities was the biggest challenge of implementing this approach, and experienced teachers who were considering this approach for the first time consistently cited this issue as one of their greatest concerns. To help address the challenges of managing the inquiry process, we developed the Collaboratory Notebook. The Collaboratory Notebook is a structured hypermedia environment that supports asynchronous collaboration across a network (Edelson, Gomez, \& Pea, 1996a; O'Neill \& Gomez, 1994). To support inquiry using the Climate Visualizer, the Collaboratory Notebook and the Climate Visualizer were bundled together as one application. Like other structured hypermedia, collaboration environments designed for learners, such as CSILE (Scardamalia \& Bereiter, 1994; Scardamalia, Bereiter, McLean, Swallow, \& Woodruff, 1989), Inquire (Hawkins \& Pea, 1987), and CaMILE (Guzdial et al., 1995), the Collaboratory Notebook uses structure as a form of scaffold. The Collaboratory Notebook provides a structure based on a task model of scientific inquiry that encourages students to organize their work into such components as questions, conjecture, evidence, plans, information, and commentary. By combining it with the Climate Visualizer, we sought to create a place for students to plan and record their investigations, coordinate work efforts among collaborative teams, and receive feedback from teachers and mentors.

\section{Issues Raised by Classroom Experiences}

Although our initial experiences with the Climate Visualizer in classrooms showed that we had increased the accessibility of visualization as an investigation technique, we were confronted by unanticipated obstacles to accessibility as well as issues for motivation and compatibility with classroom constraints.

Accessibility. One concern we had about the use of the Climate Visualizer in classrooms was that it was not being used for the full range of investigation techniques it was designed to support. The Climate Visualizer was designed as an environment for the visual interpretation of data. However, in classrooms it was primarily used as an interface for making queries about data values in specific locations. In the visual interpretation of data, a user looks for patterns in a visualization that are revealed by the variations in color across an image. For example, an expert looks for both smooth trends and sharp discontinuities in color. This process plays a role in meaning-making by revealing patterns that require explanation or that provide 
evidence for a hypothesis. For example, a novice looking at the visualization of temperature in Figure 2 might see the darker regions in the middle of the North American and Eurasian continents as a curious pattern that needs explaining. An expert would see those same patterns as evidence that proximity to the oceans has a moderating effect on temperature. The features of the Climate Visualizer that supported visual interpretation were the ability to customize the display by changing the color mappings, to display the quantitative difference between two images, to view multiple variables in the same visualization, and to view multiple visualizations simultaneously. However, the activity described previously, in which students used the Climate Visualizer as an interface for locating data about a particular place and time, was characteristic of most of the use of the Climate Visualizer. In this use, each visualization is serving as a visual interface to a database of individual values, rather than as an interactive image to support visual interpretation of data. This use failed to take advantage of the real power of visualization and was, in fact, a questionable use of the particular data in the Climate Visualizer.

In reflecting on the discrepancy between our intended use of the Climate Visualizer and the actual use, we recognized that we had only partially removed the barriers to accessibility of visualization. Although we had responded to the technological barriers through a supportive interface, we had not addressed an important conceptual barrier. We had failed to provide teachers and students with an understanding of the full range of visualization techniques that the Climate Visualizer was designed to support and the role those techniques could play in facilitating interesting investigations. An illustration of the difference between the teachers' conceptions of the use of the Climate Visualizer and the designers' is provided by an activity that one teacher designed and conducted in his earth science classes. In this activity, groups of students were each assigned a major city in the area covered by the data. They were asked to graph the weather experienced by that city for a specific month over a 25 -year period. To conduct this investigation, students called up 25 visualizations, sampled the data point that included their assigned city, entered the data into a spreadsheet, and then graphed it. In addition to the fact that this activity only used the Climate Visualizer as an interface to point data, it was also a problematic use of the Climate Visualizer's data. Because of the coarse resolution of the data $\left(2^{\circ}\right.$ latitude by $4^{\circ}$ longitude) and the fact that much of the data was based on models not measurements, the data set was not actually a reliable source of values for individual cities. When the data set was created, it was intended to support investigations of processes extending over large regions, not individual cells.

Although we were disappointed that we had not obtained the full use of the Climate Visualizer that we had sought, we learned an important lesson from this experience. It demonstrated the role a curriculum consisting of structured inquiry activities could play in providing students with models of investigation techniques and their value for pursuing research questions. In retrospect, we realized that we 
had relied too much on the tool itself to provide teachers and students with an activity model for visualization. Unfortunately, when the teacher stepped into the breach, he too lacked appropriate models of use to guide his design. Thus this experience also taught us about the need to provide teachers with good conceptual models of the tools' uses as well. In later efforts, we addressed this conceptual barrier to accessibility by creating curricula incorporating structured inquiry activities to accompany the software to provide teachers and students alike with experience showing the range of available inquiry techniques and their value for conducting investigations.

Motivation. A related concern raised in these classroom experiences was that the Climate Visualizer saw little use in extended or open-ended investigations. Only 7 of more than 353 students chose to use it in their student-directed research projects. There are a number of reasons for this lack of adoption, including the incomplete understanding of the Climate Visualizer's capabilities and value that we discussed previously. However, our observations and conversations with teachers and students led us to recognize that another part of the problem was that the design failed to address student motivation adequately. The intersection between the data sets in the Climate Visualizer's library and the interests of students was small and hard for students to see. The result was difficulty with both creating initial engagement and maintaining engagement over the longer term.

The problem with initial engagement showed up when students were given the opportunity to "play with the data" in an exploratory fashion, our recommended initial use of the software. The value of the data for investigating general weather patterns in the Northern Hemisphere and specific large-scale weather events was not particularly compelling to students with no additional introduction. They did not have sufficient background in weather to find the observable weather patterns interesting, and they had no memory of the major weather events covered by the data or other means to identify them. As we reported above, the most common exploratory activity that students performed was to look for data about the date and place they were born. Answering this question was clearly motivating. Almost universally when students were invited to "explore" the data, they started with this activity, spontaneously "inventing" it when it wasn't suggested to them. However, this investigation was almost always followed by a visible letdown when students found the answer. After they had compared with their friends, there was no place to go with the information. In general, this investigation turned out to be a dead-end activity for students because it did not lead students to notice or be interested in other aspects of the data. To our great disappointment, it was extremely rare for students to spontaneously pose other questions or to browse through data sets to look for interesting or curious patterns. 
The problem of maintaining engagement with the Climate Visualizer showed up in those cases when its use did lead students to raise their own questions, because those questions, more often than not, could not be pursued within the tool. The fact that the data were limited to meteorological variables and they only covered a portion of the Northern Hemisphere meant that many of the questions raised by students were not researchable within the tool. For example, some students expressed interest in investigations of Africa but were thwarted because the data only covered the Northern Hemisphere. Others asked about the causes and effects of the weather phenomena that the Climate Visualizer displayed and about the relation between climate and human activities, but they were unable to access any data about physical or human geography to explore these questions. Finally, both teachers and students repeatedly asked if it were possible to investigate global warming, a scientific controversy that was receiving considerable press coverage at the time. This failure to maintain engagement was particularly disappointing because in these instances the Climate Visualizer was serving its desired goal of fostering interest on the part of learners but was then frustrating them by not allowing them to pursue the interests it had raised. Although we were disappointed by the inability of the Climate Visualizer to capitalize on these expressions of interest, they helped to convince us of the ability of climate science to connect to the interests of students, particularly by the large number of students and teachers who expressed interest in investigating global warming.

With the benefit of hindsight, the reason the Climate Visualizer failed to engage students as we had hoped was clear. The tool was designed by adapting a set of scientific practices without taking adequate account of the differences between the interests of scientists and high school science students. The recognition of this challenge to motivation led us to purse two important strategies in subsequent designs. First, we selected data sets to support investigations that we had reason to believe would interest our population of students. Second, we created curriculum and activities designed to create initial engagement on the part of students that capitalize on that engagement to motivate extended, open-ended investigations.

Practical constraints. The final design problem with the Climate Visualizer was a practical failure to meet the constraints of the classroom. The software, as we had designed it, took too long to display visualizations to be practical in a classroom setting. The need to transfer data across the network and the computation involved in generating visualizations on the high-end personal computers of the time ${ }^{2}$ meant that students could experience a delay of up to a minute between requesting an image and viewing it. In a 50-min class, this reduced the productivity of students sig-

\footnotetext{
${ }^{2}$ The Climate Visualizer and the Radiation-Budget Visualizer were used on Apple Macintosh Quadra 700 computers, which were high-end personal computers at the time.
} 
nificantly, particularly because their attention typically wandered during the delay. In subsequent designs, we experimented with several different strategies to improve performance in an effort to address this problem.

\section{THE RADIATION-BUDGET VISUALIZER}

The design of the Radiation-Budget Visualizer ${ }^{3}$ addressed several of the issues exposed by our experiences with the Climate Visualizer. For example, in the development of the Radiation-Budget Visualizer, we assembled a data library around the motivating issue of global warming. We also developed a curriculum to introduce visual interpretation and data analysis activities to students and teachers. Finally, we modified the software architecture to improve its performance.

\section{Data Library}

In contrast to the Climate Visualizer's regional data, the Radiation-Budget Visualizer's data sets covered the entire world. These global data sets were selected to support investigations of energy transfer in the earth-atmosphere system and the influence of the sun, Earth's physical geography, and the atmosphere on temperature. The Radiation-Budget Visualizer's variables included incoming solar energy (insolation), earth-atmosphere reflectivity (albedo), terrestrial absorbed solar energy, outgoing long-wave radiation, net energy balance, the greenhouse effect, and surface temperature. The data showed monthly averages for one year, 1987. In addition to the data based on measurements of the actual Earth, the Radiation-Budget Visualizer also included data showing two hypothetical scenarios, an Earth with no atmosphere and an Earth with an atmosphere but no clouds.

\section{Software Architecture, Features, and Interface}

Like the Climate Visualizer, the Radiation-Budget Visualizer was implemented as a front-end to Transform. It displayed visualizations in the same two-dimensional grid format, dynamically displaying the latitude and longitude position of the cursor and the data value at that position. It improved on the Climate Visualizer's performance by storing all of its data on the local computer, removing the need to transfer data across a network before rendering them.

\footnotetext{
${ }^{3}$ The term radiation-budget is used by scientists to refer to the balance between incoming and outgoing energy in the earth-atmosphere system, which determines whether the earth experiences a net cooling or warming over a specific period of time.
} 
The interface to the Radiation-Budget Visualizer's data library was spare. It consisted of a menu for selecting a month of the year and a table for selecting the variables to view. Each column in the table represented one of the three models of the earth (i.e., the earth as observed, the earth modeled without clouds, and the earth modeled without an atmosphere), and each row corresponded to a variable. Thus a user could request a visualization of a variable under a specific model by selecting the appropriate cell of the table.

\section{Curriculum Design}

The Radiation-Budget Visualizer was designed to support activities in which learners compare data for the two hypothetical scenarios to the actual earth system values. In particular, the scenarios enabled students to investigate the role of clouds and the atmosphere in determining global climate. To help foster appropriate use of the Radiation-Budget Visualizer, we worked closely with an environmental science teacher to develop a structured, inquiry-based activity for it. The activity design took the form of a two-page handout with instructions for tasks to do with the Radiation-Budget Visualizer and nine questions to answer. The handout was very similar to the hands-on laboratory activities to which the teacher's students were accustomed. The activity began with very specific instructions for simple data-querying tasks (e.g., identify the incoming solar radiation, albedo, and surface temperature for Chicago in February 1987), then moved to questions that asked for visual interpretation (e.g., identify the relation between solar radiation and surface temperature), and then open-ended questions with no specific instructions (e.g., what is the influence of clouds?). The progression of this activity from simple activities to complex and from specific instructions to open-ended tasks was designed to expose students to the techniques of visualization in a guided fashion initially and then allow them to gain experience deciding which techniques to use through more open-ended tasks.

Use

The Radiation-Budget Visualizer was released to participants in the CoVis Project in the winter of 1994 and was used by one environmental science teacher that year. It was also used to support research projects by a few students in the classes of two Earth science teachers that year.

Issues Addressed by the Design

The design of the Radiation-Budget Visualizer and its accompanying curriculum activity attempted to address motivation, accessibility, and practical constraints. 
The greenhouse investigation activity was intended to address challenges to both motivation and accessibility. The activity was designed to capitalize on the global warming controversy as a motivating context by introducing the greenhouse effect and leading students through an investigation of it. It addressed the accessibility issue raised by the Climate Visualizer by introducing students to the range of investigation techniques supported by the tool. In practice, we observed that the early questions with more specific instructions helped introduce students to the process of looking for patterns in data. Although the depth of their analyses and the quality of their answers varied widely, we did observe students using the Radiation-Budget Visualizer to support the sort of visual interpretation we had missed with the Climate Visualizer.

The change in data sets was designed to address the challenge of motivation. The incorporation of data showing the greenhouse effect was designed to capitalize on the motivating aspects of the global warming controversy.

The practical constraints of the classroom were addressed in the design of the Radiation-Budget Visualizer by removing the need to transfer any data across the network. This improved performance, but, as we also note in the following, did not adequately address the challenge of meeting classroom constraints.

\section{Issues Raised by Classroom Experiences}

Our classroom experiences with the Radiation-Budget Visualizer were limited, but they helped us to focus on an important issue of background knowledge that we had observed but not addressed previously, and they revealed that we had not adequately met the challenge of practical classroom constraints.

The need for background knowledge to support investigations became a clear issue with the Radiation-Budget Visualizer. Although the Climate Visualizer inadequately addressed the need for background knowledge as well, it was not as clearly apparent in classrooms because of the limited way in which it was used. In the class that used the Radiation-Budget Visualizer, students were often confused by the interface to the data library because it relied on their understanding what each of the variables and the hypothetical models represented. Understanding what the data sets in the tool represented and their relation to natural processes was the goal of the activity, but the design of its user-interface made them prerequisite knowledge for using the tool. As a result, it fell to the teacher to provide explanations for the variables and models in the user-interface. However, because activities were conducted in self-paced groups, the teacher was faced with the dilemma of explaining things to the whole class at one time when the information was relevant to some groups and not others, or to be available for each group when they required it. One of the reasons that the other teachers cited for not using the Radiation-Budget Visualizer in their classes was that they were concerned about 
their ability to provide their students with the background knowledge that they felt the tool required.

The final obstacle to inquiry-based learning with the Radiation-Budget Visualizer was that the new architecture had only partially achieved the objective of meeting the practical constraints of the classroom. As with its predecessor, the computational requirements of rendering visualizations from large data sets strained the capacity of the classroom computers. The slow performance remained a problem for use in standard-length class periods. In addition, the storage requirements of the data sets and the cost of the commercial application Transform meant that the Radiation-Budget Visualizer was not suitable for broad distribution to schools.

\section{THE GREENHOUSE EFFECT VISUALIZER}

The Greenhouse Effect Visualizer (Gordin, Edelson, \& Pea, 1995) succeeded the Radiation-Budget Visualizer and was the first of the visualizers that was suitable for broad use. The Greenhouse Effect Visualizer was created by simplifying the Radiation-Budget Visualizer and adapting it to the World Wide Web. In developing curriculum to accompany the Greenhouse Effect Visualizer, we attempted to addressed the issue of motivation even more completely by creating an expanded curriculum unit that connected the science more directly to the social and political implications of global warming. The issue of background knowledge was addressed by incorporating documentation and scientific explanations into the user-interface, and the constraints of the classroom were addressed by moving to a web-based interface. In addition, with the Greenhouse Effect Visualizer, we introduced a new aspect to the visual interpretation of data by providing data sets at multiple temporal and spatial resolutions.

\section{Data Library}

The Greenhouse Effect Visualizer displayed the same variables showing the transfer of solar energy through the earth-atmosphere system as the Radiation-Budget Visualizer. However, the data showing the hypothetical models of the earth with no clouds and no atmosphere were eliminated to simplify the interface and reduce the storage requirements. A new feature of the Greenhouse Effect Visualizer's data library was the inclusion of data for a variety of temporal and spatial resolutions. Each variable was available at monthly, seasonal, and yearly temporal resolutions, and at $2.5 \times 2.5,5 \times 5,10 \times 10,20 \times 20,60 \times 60$, and $360 \times 180^{\circ}$ spatial resolutions. The objective of making these different resolutions available was to enable students to explore patterns and averages over different temporal and spatial scales. This is particularly important for investigating global warming, for which the im- 
pact is characterized by a change in an annual, global average, whereas its impacts and causes are distributed throughout the world and across the year. As with the Radiation-Budget Visualizer, the data only covered 1987.

\section{Software Architecture, Features, and Interface}

The architecture for the Greenhouse Effect Vis alizer departed dramatically from its predecessors. In the Greenhouse Effect Visualizer, all the available visualizations were rendered in advance and stored on a web server. Users accessed data by selecting a variable, time interval, and spatial resolution from a list (Figure 4). Visualizations were displayed in interactive web pages that allowed the learner to select a point in a visualization and view its latitude, longitude, and data value (Figure 5). The use of the World Wide Web greatly reduced the computational require-

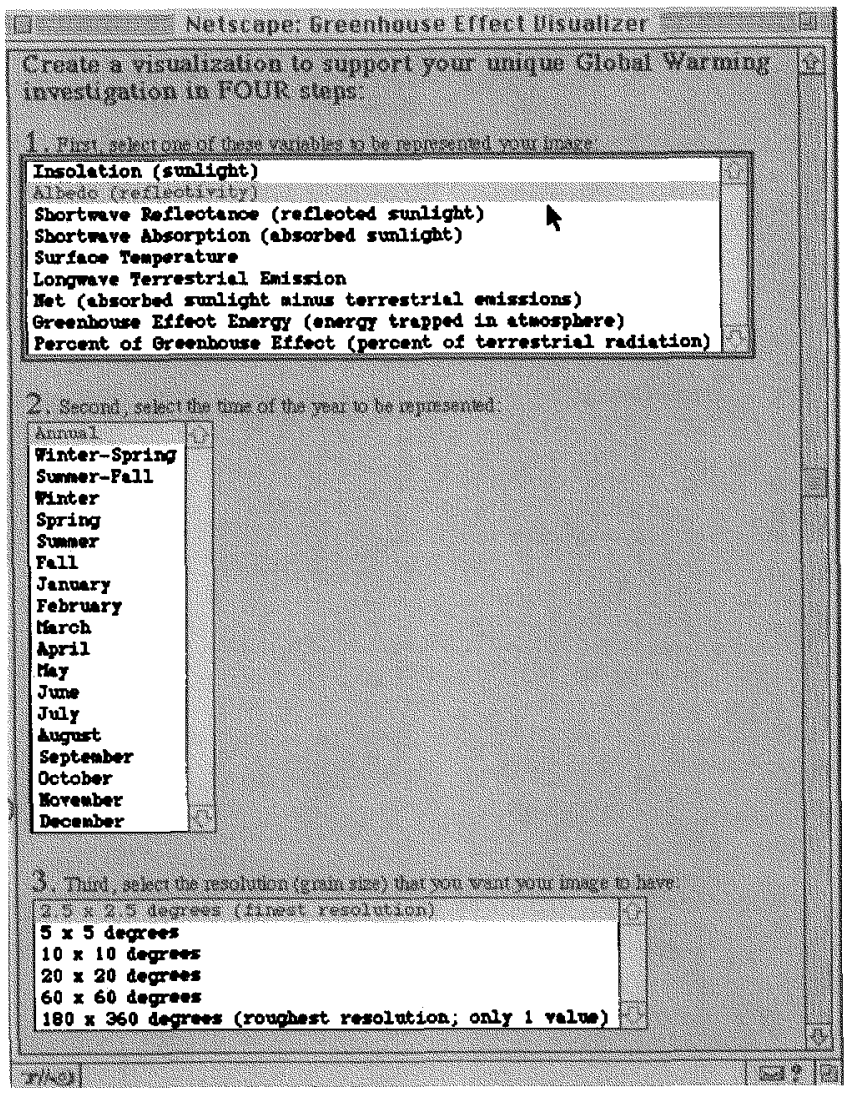

FIGURE 4 The interface to the data library in the web-based Greenhouse Effect Visualizer. 


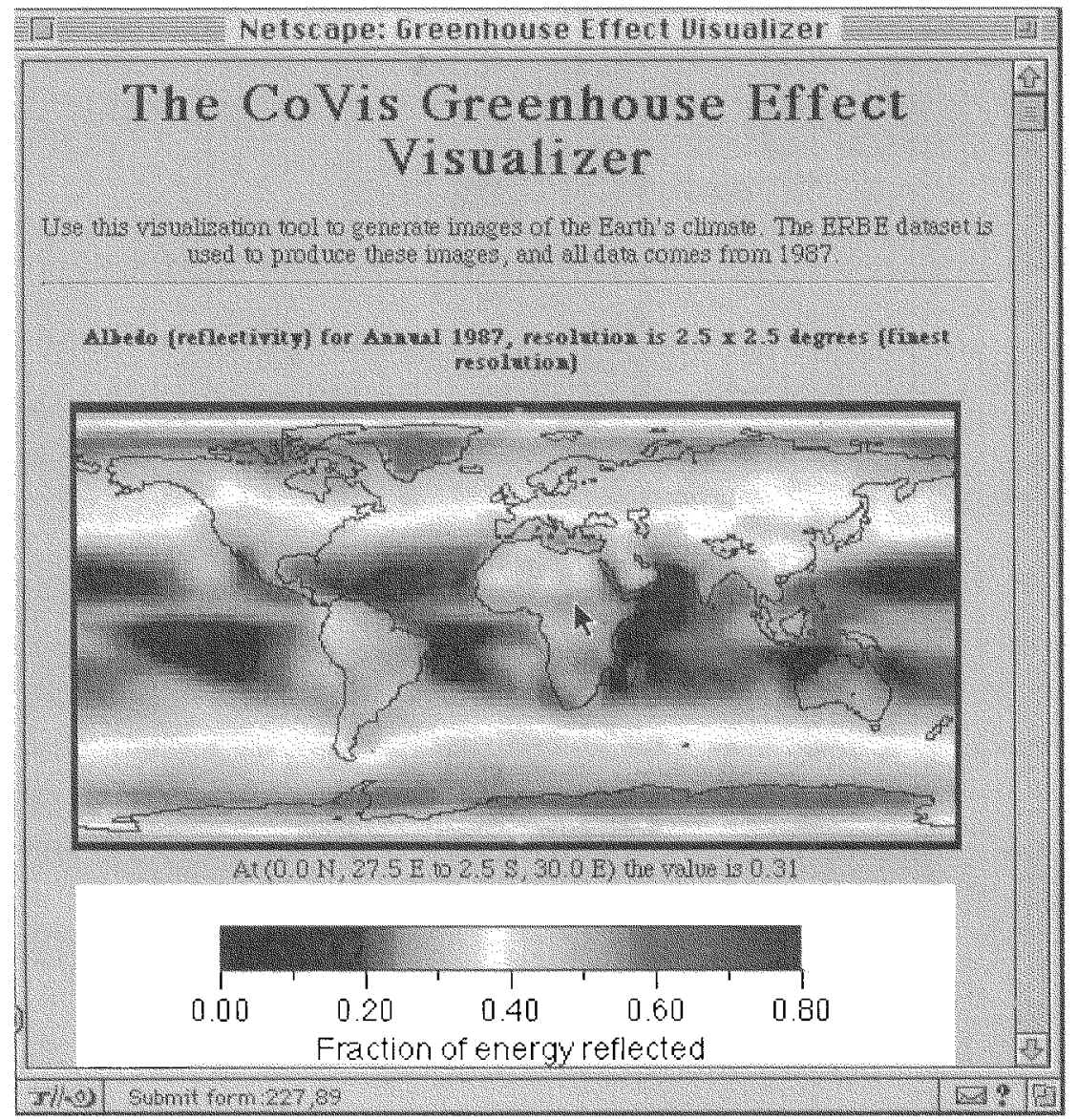

FIGURE 5 Data displayed in the web-based Greenhouse Effect Visualizer.

ments needed to access the visualizations, although it added the requirement of an Internet connection. In addition, the performance was improved over the previous visualizers by generating all of the images in advance and caching them on the server. Because of the need to prerender all the visualizations, however, the ability to customize the display of data by modifying the color palette or mapping of colors to values was eliminated.

The other major addition to the Greenhouse Effect Visualizer was the inclusion of explanatory materials linked to the visualization interface. This material provided explanations of the individual variables available in the Greenhouse Effect Visualizer as well as a description of the basic energy balance cycle that was illustrated by visualizations from it. 


\section{Curriculum Design}

In the fall and winter of 1995-1996, we developed a 5-week project-based curriculum entitled The Student Conference on Global Warming. In contrast to the narrow focus on the greenhouse effect of the activity developed for the Radiation-Budget Visualizer, the Global Warming Conference covered a wide range of scientific issues associated with the global warming controversy. The development of the Global Warming Conference was part of a new focus in the CoVis project on the development of extended curriculum. Unlike the Radiation-Budget Visualizer activity, it was not developed specifically around the opportunities provided by scientific visualization techniques. The conference was designed to be an engaging, coherent, inquiry-based unit to achieve learning objectives in earth and atmospheric sciences. In doing so, it took advantage of the global warming controversy as a unifying, motivational context. As an extended inquiry-based unit, it drew upon a number of investigation techniques and sources of data, only one of which was the Greenhouse Effect Visualizer. The overall curriculum consisted of a 2-day introduction to the global warming controversy, a 2-week sequence of structured 1to 2-day inquiry activities, and a 2-week open-ended investigation of a specific global warming issue or country. The project unit culminated in a mock international conference on global warming that could be conducted either within a single classroom or by classes in multiple schools over the Internet.

The structured activities introduced learners to the science and controversies surrounding global warming. One of these activities took advantage of the Greenhouse Effect Visualizer to explore seasonal changes in solar radiation and their influences on Earth's surface temperatures. In the first part of this activity, students looked at incoming solar radiation at several different spatial resolutions to help develop an understanding of the concept of spatial averaging. They then were asked to characterize the way that incoming solar energy varied by latitude and by season and to explain this variation using knowledge they had gained through a prior activity in which they looked at the tilt of the earth's axis relative to the sun in different seasons. In the final part of the activity they compared surface temperature visualizations with incoming solar energy to characterize the relation between solar energy and temperature (Figure 6).

The curriculum materials for this activity included a handout for students that provided instructions for each stage of the activity and questions for students to answer. ${ }^{4}$ This activity called for students to employ all of the visualization operations of the Greenhouse Effect Visualizer. It called for them to use the variable spatial resolutions to explore the relations between local variation and global average. It called for them to engage in visual interpretation to characterize large-scale patterns and to compare energy visualizations with temperature. Finally, it called for

\footnotetext{
${ }^{4}$ In practice, most teachers modified the handout to suit their own objectives.
} 


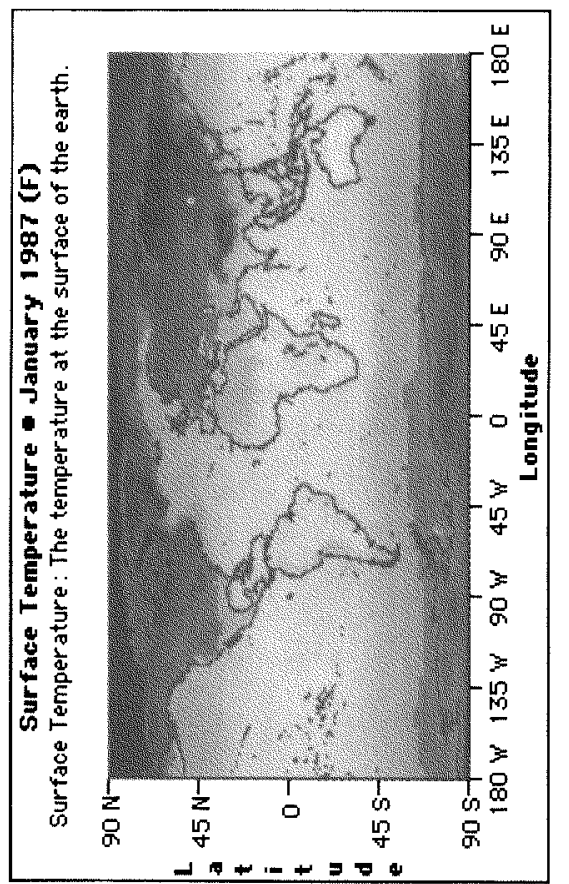

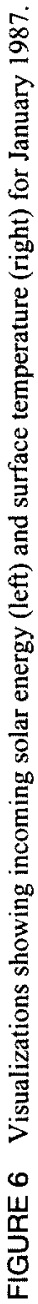

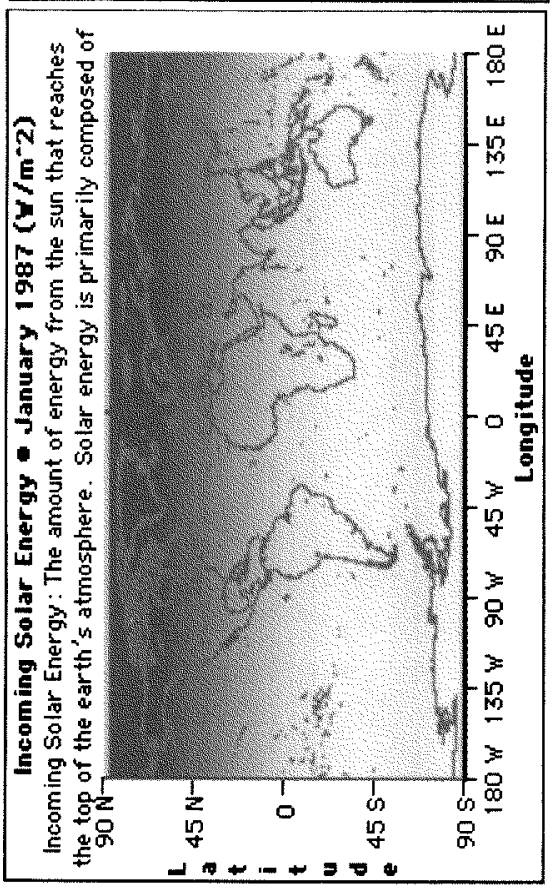


them to use the data sampling capability to find specific numerical values for specific locations. The sequencing of this activity among the structured activities and the introduction to it that was provided for teachers and students were designed to place it in context within the larger framework of the global warming controversy. The structured activities were presented as an exploration of natural and unnatural variation to answer the larger question, "Are human emissions of greenhouse gases contributing to global warming?" The different activities looked at natural and "unnatural" variations in a number of greenhouse-related variables over a variety of time scales, and this one focused on natural variation over seasonal and annual intervals.

\section{Use}

The Greenhouse Effect Visualizer was first used by the environmental science teacher who had previously used the Radiation-Budget Visualizer in the spring of 1995. She used it for a unit on global warming that helped shape the design of the Global Warming Conference curriculum (Gomez, Gordin, \& Carlson, 1995). The Greenhouse Effect Visualizer was then made available for a broader audience of schools in the 1995-1996 school year, a year in which the CoVis project expanded from 2 local schools to approximately 25 schools scattered throughout the eastern United States. In that year, the Greenhouse Effect Visualizer and its accompanying curriculum were used by 24 middle and high school teachers in the CoVis Project. In addition, we received reports from many non-CoVis teachers, including community and 4-year college instructors, who had integrated the Greenhouse Effect Visualizer into classes on earth, atmospheric, and environmental science.

\section{Issues Addressed by the Design}

The design of the Greenhouse Effect Visualizer and the curriculum for the Global Warming Conference addressed several issues raised by our prior experiences, specifically, motivation, accessibility, background knowledge, and practical classroom constraints.

The Global Warming Conference curriculum was designed with the explicit goal of connecting the climate science to the societal implications of global warming. This curriculum was designed to introduce the scientific controversy over global warming and contextualize the investigations of the greenhouse effect using the Greenhouse Effect Visualizer as part of understanding how global warming might occur and how it might be affect energy and temperature data. The role of the mock international conference in the curriculum was to create a demand for this understanding of the greenhouse effect to deal with the larger social, eco- 
nomic, and political implications of global warming. Although students found the issue of global warming motivating and were engaged by the Global Warming Conference, we still observed problems with the alignment of the motivation and the learning objectives, which we discuss in the next section.

The Global Warming Conference curriculum was designed using a framework that was intended to address both the challenge of making investigation techniques accessible and the need for background knowledge. This framework, which became the backbone for all curriculum units developed by CoVis, took advantage of a class of activities that we call staging activities. The curriculum framework begins with an introductory, or hook, activity that was designed to create interest in the question or controversy covered by the curriculum. This is followed by staging activities, which are short, structured investigations designed to build understanding of the relevant investigation techniques and help develop scientific understanding. In an approach that is similar to the progression from problem-based to project-based learning described by Barron et al. (1998), staging activities are designed to provide the background necessary for students to engage in an extended, open-ended investigation that follows them. This open-ended activity builds to a culminating, performance-based activity in which students apply the knowledge gained through the curriculum sequence. Thus staging activities address the challenge of making investigation techniques accessible by introducing them in a structured, guided activity, and they address the need for background knowledge to conduct open-ended inquiry by providing its acquisition in the context of individual investigations.

The need for background knowledge was also addressed in the Greenhouse Effect Visualizer by linking explanatory materials directly to the Greenhouse Effect Visualizer interface. These explanations were added to provide support for teachers and students in understanding the nature of the data, how it was generated, what it measures, what the units are, and how it can be used to understand climate processes. Explanations of the fundamental processes of energy transfer in Earth's energy cycle were also included, such as reflection and absorption of solar shortwave radiation, emission of longwave radiation by the earth, and the absorption and emission of longwave radiation by the atmosphere (greenhouse effect). Teachers reported that these explanatory materials were valuable both for preparing themselves and for supporting students during their use of the Greenhouse Effect Visualizer.

As for practical constraints, the adoption of the web-based interface allowed us to make a supportive visualization environment available to a broad audience of learners for the first time. Rather than requiring high-end personal computers with large amounts of memory and disk space, the Greenhouse Effect Visualizer could be accessed from any Internet-connected computer with a color monitor and enough memory to run a web browser. It was, in fact, used in classrooms with a wide variety of technology infrastructures. 


\section{Issues Raised by Classroom Experiences}

Although the Greenhouse Effect Visualizer represented a breakthrough in the number of schools who used it, observations and reports of use still raised important concerns about motivation, accessibility, background knowledge, and practical constraints.

Motivation. The Global Warming Conference curriculum was intended to provide a motivating context for learning about climate based on concern over the implications of global climate change. This context was designed to motivate not just the visualization activities using the Greenhouse Effect Visualizer but also the other structured investigations involving data, graphing software, modeling software, and hands-on laboratory experiments. In practice, we found that teachers struggled to present the curriculum to their students as a coherent whole. In several cases, teachers chose to focus on the structured investigations, treating them like a traditional curriculum unit organized around a topic, not a controversy. Other teachers chose to focus on the societal implications and de-emphasized the inquiry activities and the climate science. Only a handful of teachers actually conducted a mock conference, and those that did found it difficult to connect the science content to the social, economic, and political issues that were the subject of the conference. Although teachers responded quite favorably to the curriculum, and most who conducted it in 1996 repeated it in 1997 , their positive feedback was based on individual activities that they found valuable rather than the overall motivating structure. Based on these results, we decided that global warming was, in fact, a motivating context but that the curriculum had to be more carefully constructed to align the science investigations with the culminating activity.

We became aware of a new challenge for accessibility and motivation through our observations of the Greenhouse Effect Visualizer in use. We started to become aware of populations of students who were following instructions and identifying patterns in data but did not show any curiosity about the phenomena in the patterns they observed. Their responses contrasted with other students we had observed who found the same patterns to be surprising and intriguing and were easy to engage in the process of constructing explanations for their observations. One of the places we observed this was in a structured investigation of seasonal and geographic differences in temperature that was similar to the seasons activity described previously. The activity was designed to present students with discrepancies in the patterns of incoming solar energy and surface temperature in a way that would elicit curiosity about the sources of differences. For example, although New York and Madrid receive approximately the same average solar radiation in January, their average tem- 
perature differs by approximately $20^{\circ} \mathrm{F}$. In fact, many students did find the differences between the neat horizontal bands of incoming solar energy and the much messier patterns of surface temperature (Figure 6) to be intriguing, and they would spontaneously offer possible explanations. However, we became increasingly aware that there were many students who recognized the difference in the patterns and could describe these differences without finding them remarkable or feeling a need to explain them. These students were participating in the activity in a mechanical fashion. They were not actively resistant or uninterested; the activity just failed to engage them. Because the students were noticing curious phenomena without becoming curious about them, we conjectured that they were not entering the activity with sufficiently strong expectations about the phenomena they were observing.

To address this problem, we looked for a design solution that would be more effective in activating expectations on the part of students. The solution we developed was an introductory activity in which students drew their own visualizations of temperature with crayons on blank maps of the world. In this activity, students were asked to draw on any prior knowledge they might have to produce their best guess of what the average temperatures are like for a particular month of the year (Figure 7). Students frequently describe their experience of this activity as demonstrating both how much they know about temperature that they didn't realize and also how much they don't know. In effect, the activity is an exercise in articulating prior conceptions, which Hunt and Minstrell (1994) have shown to be effective in enabling learners to connect new knowledge to old. However, the critical role it was playing in our activities was activating expectations and eliciting curiosity. We found that after creating these visualizations representing their preconceptions, students approached the investigation of temperature variation with open questions and active expectations that produced noticeably more interest in the subsequent seasons investigation.

After introducing this activity, we recognized it has other benefits as well. It introduces the color map representation by having learners use it expressively before they use it intepretively. It also creates a bridge to the highly technical activity of visualization through an activity that learners are already familiar with and enjoy, drawing with crayons. In fact, we have come to call this type of activity a bridging activity. Bridging activities are designed with the explicit goal of providing them with the context or knowledge they require to engage successfully in more scientific activities. Unlike the investigation activities that are adapted from scientific practices, bridging activities are invented specifically to suit the needs of learners in bridging the gap to scientific practices. Bridging activities can address motivational, accessibility, and background knowledge issues. Following on the success of this activity, we incorporated a visualization-drawing activity into the Global Warming Conference curriculum and incorporated a drawing feature into the design of subsequent visualization environments. 


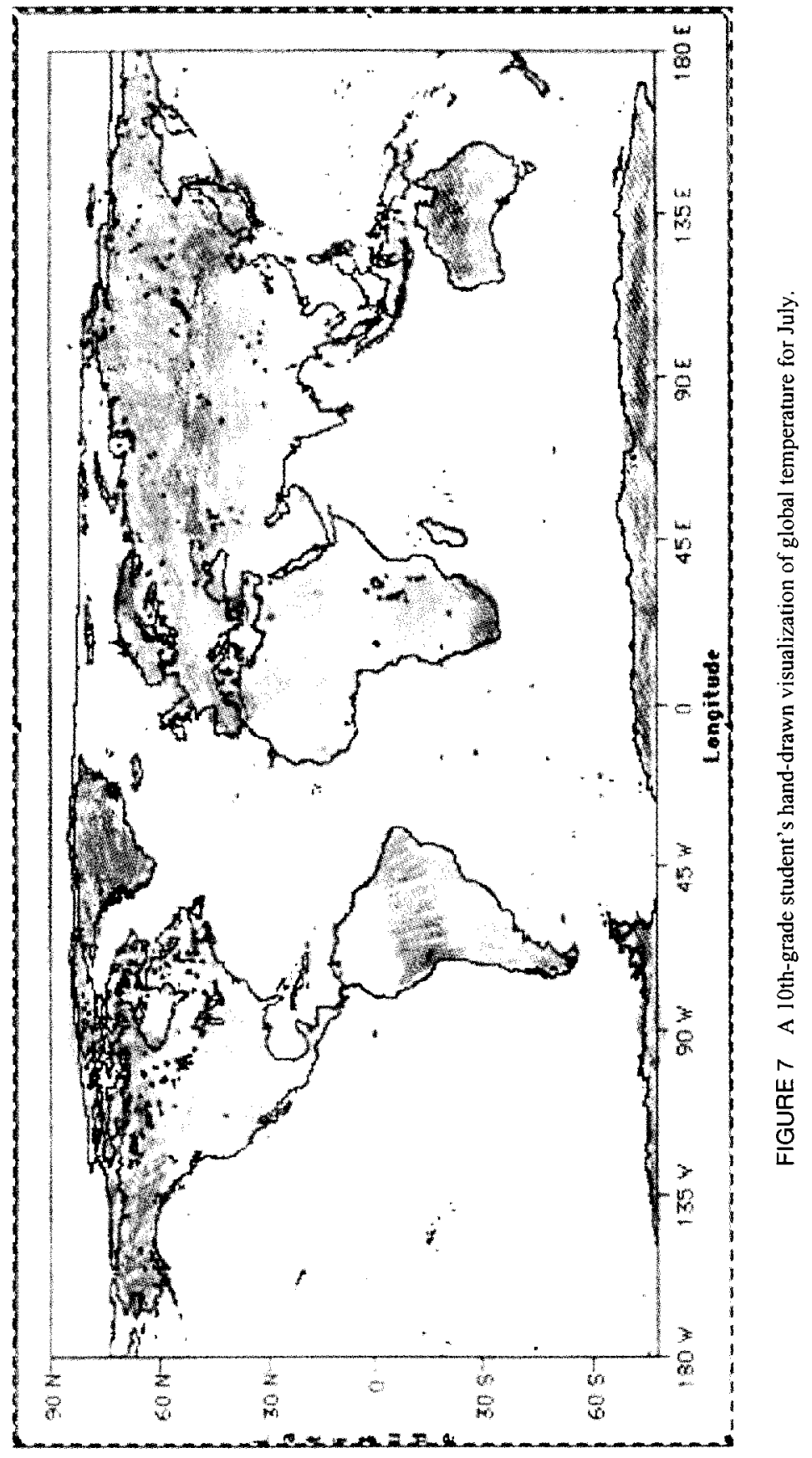


Accessibility. An important issue for the accessibility of investigation techniques became apparent after the Greenhouse Effect Visualizer was in use for some time. Although the Greenhouse Effect Visualizer and its curriculum had made short, structured investigations accessible to learners within the constraints of classrooms, it was not being used for extended or open-ended inquiry. In retrospect, we realized that the reduction in functionality that resulted from the decision to adopt a web-based architecture with prerendered visualizations precluded the use of the Greenhouse Effect Visualizer for open-ended inquiries. The loss of the ability to customize the display of visualizations and the elimination of arithmetic operations on data sets meant the Greenhouse Effect Visualizer lacked the support required for in-depth exploration of its quantitative data. These limitations, coupled with the reduction in the available data, restricted the Greenhouse Effect Visualizer to support for a small number of short (though pedagogically important) investigations. This limitation was addressed in subsequent designs by returning to an architecture that rendered visualizations in real time and provided a large number of options for the customization of visualizations and the quantitative analysis of data.

Background knowledge. Although we found that the explanatory materials in the Greenhouse Effect Visualizer helped learners to interpret the visualizations, we found students still lacked important background knowledge for their investigations. Even with the explanations, many students had difficulty understanding the more abstract variables and their units of measurement, such as reflectivity and energy flux, which are measured in percent and in watts per square meter, respectively. As an example, we often observed students referring to areas with high influxes of radiation as "hot" because they appeared red in visualizations, even though the temperature might actually be quite cold, as in Antarctica during the Southern Hemisphere summer. In subsequent designs, this issue was addressed by designing activities that provided students with physical experiences involving these quantities and their units of measurements.

Practical constraints. Finally, in trying to meet the constraints of the classroom, we found that the dependency on an Internet connection was a problem for many schools because they had unreliable or low bandwidth network connections.

\section{WORLDWATCHER}

WorldWatcher, the most recent visualization environment in this line, continues to be the subject of active research and development. It represents an attempt to integrate all the lessons learned from the previous visualizers and curriculum. 
WorldWatcher is the first of the visualization environments to be developed by a professional programmer and, not coincidentally, represents a significant step forward in terms of software functionality. It has many more of the operations found in commercial, general-purpose scientific visualization tools, but it retains the approach to data-specific, supportive interfaces of its predecessors. The first version of WorldWatcher was released in 1996 with the name ClimateWatcher. ClimateWatcher had a data library assembled specifically for investigations of global climate change. The software was subsequently enhanced to include an open data architecture that allows users and curriculum designers to create their own data libraries. It was then renamed WorldWatcher to reflect its broader applicability.

\section{Data Library}

WorldWatcher retained the data sets from the Greenhouse Effect Visualizer showing Earth's energy balance. These data sets were supplemented by additional data displaying physical geography and human activities. The new data include Earth surface elevation, dominant ground cover and vegetation, precipitation, human population, and carbon emissions from industry. These data sets were added, in part, to allow students to examine potential causes and impacts of climate change. Although the transition to an open data architecture in WorldWatcher has made it easy to add new data sets, the climate data sets continue to be the core of the data library.

\section{Software Architecture, Features, and Interface}

With WorldWatcher we returned to a standalone, nonnetworked application to provide a level of functionality that was not possible on the World Wide Web at the time that the development began. Unlike the three previous visualizers, WorldWatcher renders its own images rather than relying on a third-party visualization application.

With its enhanced interactivity, WorldWatcher is more like the Climate Visualizer than its immediate predecessor, the web-based Greenhouse Effect Visualizer. Like all of the previous visualizers, WorldWatcher displays two-dimensional false-color visualizations in an interface that provides geographic referents, including continent overlays and latitude/longitude markings (Figure 8). It allows users to select preferred units (e.g., Fahrenheit or Kelvin), and it provides a constant readout showing the location of the cursor (both latitude/longitude and country/province) and the data value at that point. The two innovations of the Greenhouse Effect Visualizer are also retained in 


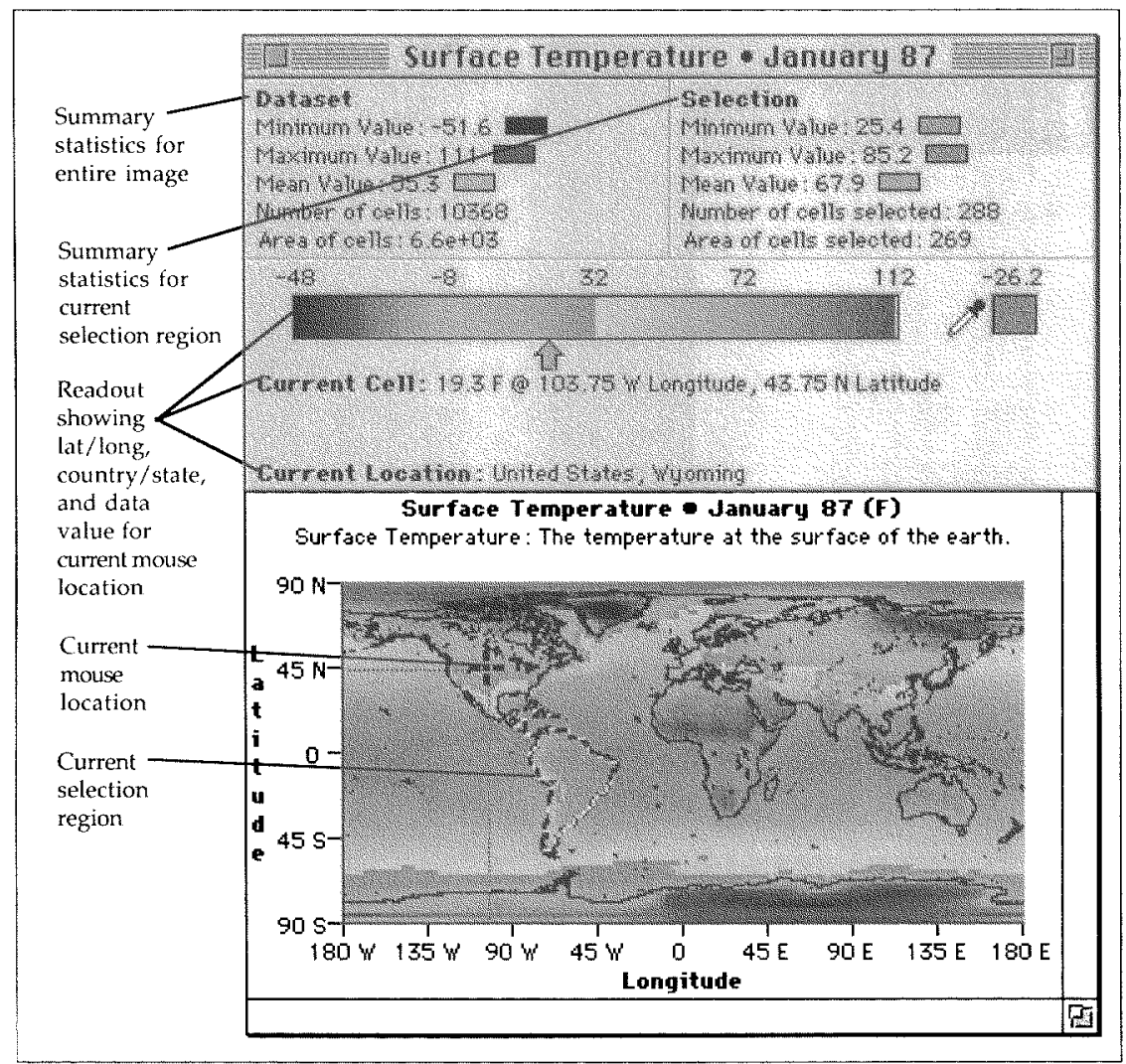

FIGURE 8 A visualization window from the WorldWatcher software displaying surface temperature for January 1987.

WorldWatcher. These are the ability to examine visualizations at varying spatial resolutions (now computed dynamically) and the inclusion of supporting explanations and materials. In addition, WorldWatcher enables users to customize the display of their visualizations by zooming and panning, changing the palette of colors used to represent data values, and changing the mapping of colors to numbers.

Besides the functions for tailoring the display of data, WorldWatcher also contains operations for analyzing and creating data with mathematical operations, for creating data using a painting metaphor, for viewing data using other visual representations, and for creating documents incorporating visualizations and hypermedia links to data sets. 


\section{Curriculum Design}

For the initial release of WorldWatcher, we adapted the Global Warming Conference to take advantage of the new capabilities of the software. In the spring of 1998, as part of the activities of the newly formed LeTUS Center, we developed a new Global Warming Curriculum, tailored to the middle school science standards for the Chicago Public Schools. The Global Warming Curriculum is a 6-week project unit in which learners prepare science briefings for the participants in a fictitious international conference on global warming. In addition, as the community of users and the range of data available in WorldWatcher grow, we have assembled a library of structured activities and open-ended investigation topics. One example is a single-session investigation of an elevation data set for Mars. A second example is a 10-hr structured investigation called the Create-A-World activity, in which students create a fictitious world and generate temperature data for it based on an investigation of Earth's climate (Edelson, 1998a).

\section{Use}

The first version of WorldWatcher (ClimateWatcher) was released in the spring of 1996. It was used by CoVis Project schools as part of the Global Warming Conference curriculum in the 1996-1997 and 1997-1998 school years. WorldWatcher was used in pilot tests of the LeTUS Global Warming Curriculum in three Chicago Public Schools in the spring and fall of 1998. It has also been used in a variety of undergraduate geosciences courses at Northwestern and elsewhere, and in several workshop-setting studies conducted by the authors at Northwestern and SRI International. More than 2,000 copies of WorldWatcher have been distributed over the Internet or on CD-ROM since 1996.

\section{Issues Addressed by the Design}

WorldWatcher and its accompanying curricula contain new elements to address all five of the challenges of implementing inquiry-based learning.

\section{Motivation}

By enhancing WorldWatcher's data library and curriculum, we have attempted to resolve the challenges of motivating inquiry more completely than its predecessors. The objective of many of these enhancements is to take better advantage of global warming as a motivating context. For example, we enlarged the data library 
to include human and physical geography data sets to support investigations of the causes and implications of global climate change that go beyond the cycle of energy transfer in the earth-atmosphere system. For example, the population and carbon emissions data sets support investigations of the population impact of predicted global warming and the contributions of different nations to the buildup of greenhouse gases in the atmosphere. The ability to investigate these causes and implications of visualization makes it easier for curriculum designers and teachers to connect the motivating social aspects of global warming to the climate science. In addition, the broadened data library also supports the goal of maintaining engagement by allowing students to pose and pursue their own research questions. This issue was raised by our experiences with the Climate Visualizer but not effectively addressed by the Radiation-Budget Visualizer or Greenhouse Effect Visualizer. WorldWatcher's larger library of related data and the ability to import new data make it possible for WorldWatcher to accommodate a much broader range of student-generated investigations than its predecessors could.

The curriculum was also revised to address some of the problems of coherence that showed up in the CoVis Global Warming Conference curriculum. In the LeTUS Global Warming Curriculum developed in 1998, the motivating context is still provided by an international global warming conference, but rather than playing the role of participants in that conference, the new curriculum establishes their role as scientific advisors to the participants. The difference is important because it directs students' attention away from the diplomatic issues of an international conference back toward the scientific issues and the potential implications of global warming and the prevention measures being considered. At each stage in the 6- to 8-week curriculum, students must prepare briefings designed for representatives of the United Nations or individual countries. These briefings motivate investigations of topics such as, "How would we know if Earth were warming?" "How could changes in the atmosphere lead to global warming?" and "Predictions and solutions."

\section{Accessibility of Investigation Techniques}

The design of WorldWatcher addresses the challenge of accessibility at both ends of the inquiry spectrum. It incorporates new features to increase the initial accessibility of scientific visualization as a technology for learning, and it introduces more powerful investigation techniques to make more extensive and sophisticated investigations possible.

Interpreting visualizations. Beginning in 1996, the CoVis Project expanded to include middle school science teachers. In conversations about the 
Greenhouse Effect Visualizer, they raised concerns about their students' abilities to interpret visualizations as gridded representations of data, as opposed to pictures or maps with colored regions. To make the basic interpretation of these visualizations more accessible, we added several features to WorldWatcher.

Two features address the challenge of understanding a visualization as a grid of numerical values. The first is an operation that allows the learner to magnify the visualization to a point where each cell in the image displays its numerical value superimposed on its color (Figure 9). This feature provides a visual analogy to spreadsheets, a gridded data representation that is familiar to many students. The second is a data creation tool that allows users to input data by painting colors on visualizations. The interface for painting data is modeled on conventional paint programs with a paintbrush for drawing cell by cell and a paint can for filling in regions. Users set a data value to paint by typing it in or by using an eyedropper to select the corresponding color from the color bar or visualization. The drawing feature picks up where the crayon-drawing activity described previously leaves off. The crayon drawing introduces the concept of color as value, but its spatial resolution is determined by the sharpness of the crayon, and the chromatic resolution is determined by the number of crayons. In the WorldWatcher tool, students are restricted to the gridded spatial layout of cells and the spatial resolution associated with a particular visualization. Similarly, in using the color bar as a paint palette, they have the numerical resolution corresponding to the 254 colors in the color bar, but they can bypass the 254 -value restriction by typing in numerical data values at a higher precision. Informal observations and teacher reports indicate that working with these drawing tools helped students to understand the relation of the visual image to the underlying data when they began working with the actual data in WorldWatcher's data library.

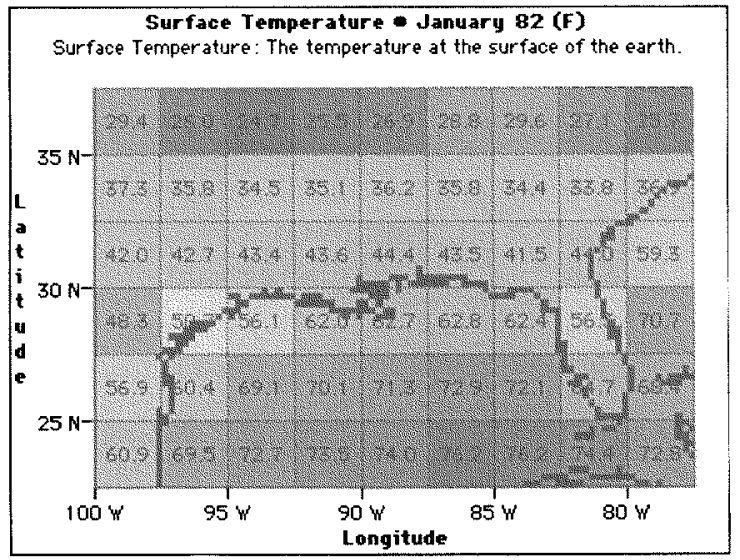

FIGURE 9 A visualization magnified to show the individual data values in each cell. 
The second concern of teachers about interpreting visualizations that we addressed in WorldWatcher was the distortion of geography involved in projecting the spherical Earth onto a rectangular grid of data. Several experienced teachers complained of having struggled to teach geometric projections to students over their whole careers. To help with this challenge to understanding, we added two additional operations to WorldWatcher. The first displays data in a projection that preserves the relative area of regions at different distances from the equator more accurately than the default rectangular projection. The second displays visualizations as cut-and-fold diagrams that can be printed out and assembled into polyhedra-resembling globes. ${ }^{5}$ Both projections are shown in Figure 10. Although neither of these provides the interactivity of the default rectangular representation in WorldWatcher, they provide opportunities for teachers to conduct bridging activities in which learners understand the effects of projection.

Locating data in the data library. In the design of WorldWatcher, we identified a new opportunity to embed the tacit knowledge drawn on by scientists in the user-interface. In the Greenhouse Effect Visualizer and many online libraries of scientific data, the interface for selecting data consists of list of variable names, which are typically a challenge for learners because of the technical nature of the names. The interfaces for selecting data in most general-purpose scientific visualization tools are generally even less accessible because they force users to locate data in files relying on the file system directory structure and file names to indicate where a particular data set can be found. In the Greenhouse Effect Visualizer, we attempted to address this problem by linking background knowledge and documentation directly to the user-interface. In WorldWatcher, we created a mechanism to allow designers to embed contextual information directly into the interface to the data library. Specifically, WorldWatcher provides for the use of conceptual diagrams as data library interfaces. For the radiation-budget data in WorldWatcher, the interface to the data library takes the form of an energy balance diagram showing the transfer of energy as it arrives from the sun and passes through the earth-atmosphere system (Figure 11).

When a user selects a particular variable name in this diagram, he or she is presented with a list of available dates from which to choose. The diagram provides a visual representation of the contents of the library and indicates how the variables relate to each other. To allow for extensions to WorldWatcher, the software provides a mechanism for any user to create these diagrammatic data interfaces.

\footnotetext{
${ }^{5}$ The inspiration for this feature was Michael Eisenberg's hypergami project (Eisenberg \& Nishioka, 1997).
} 


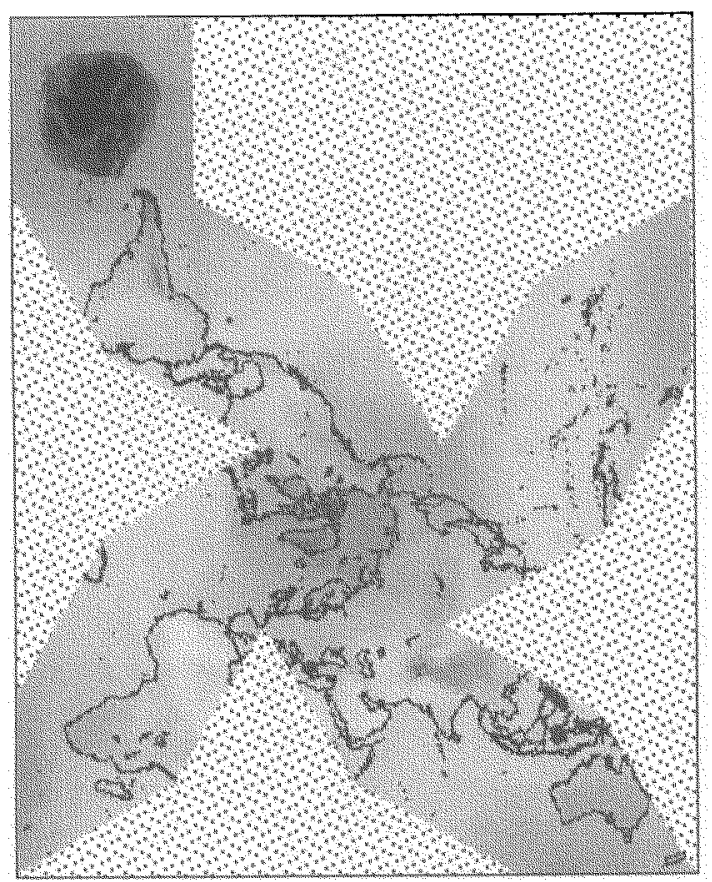

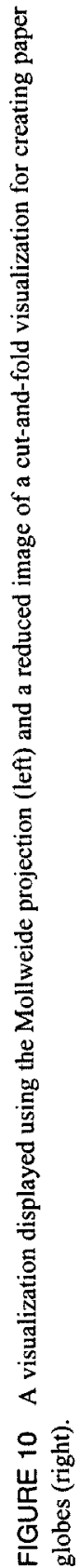




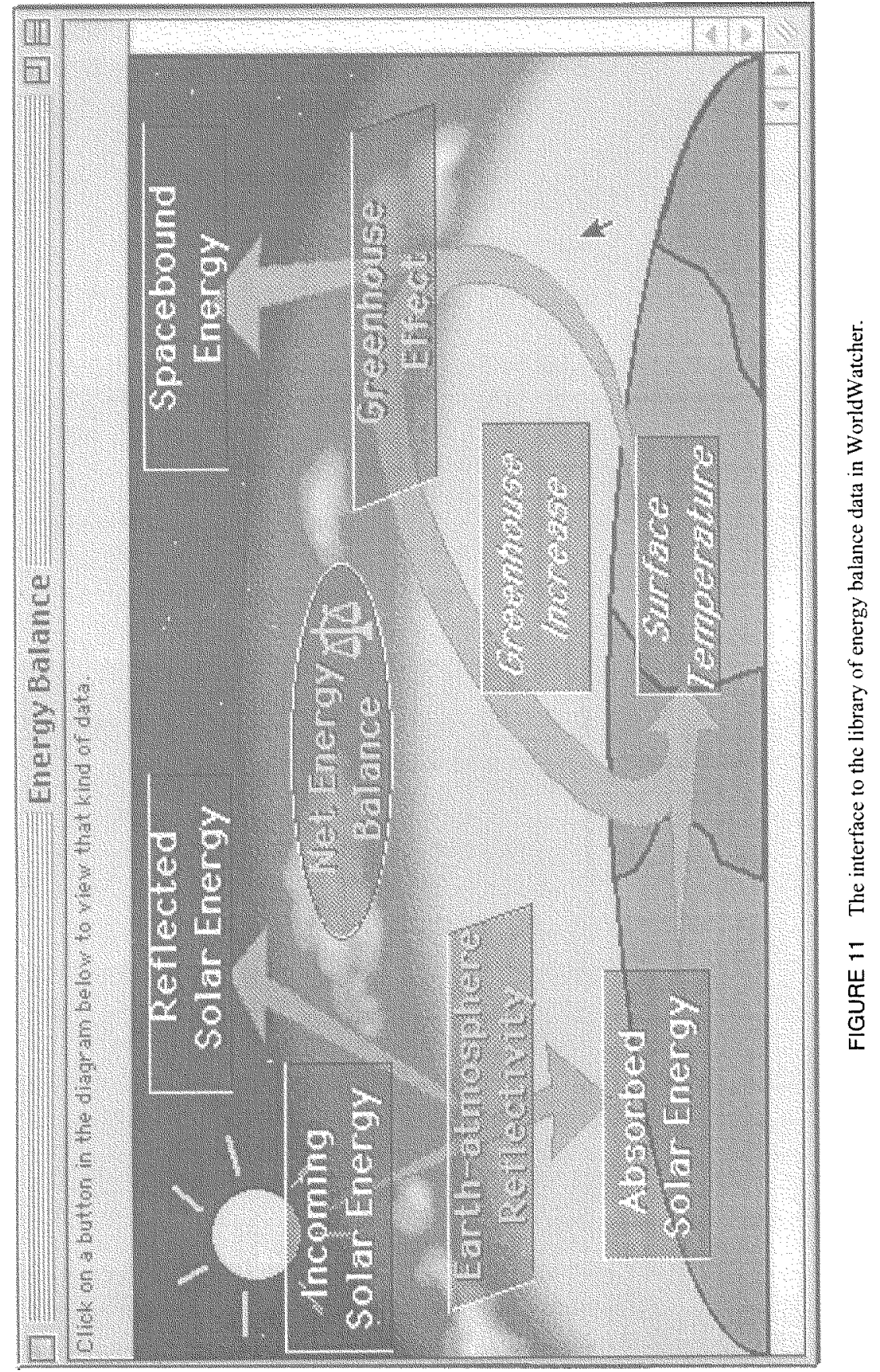


Access to powerful investigation techniques. The design of WorldWatcher also addressed accessibility at the other end of the inquiry spectrum, that is, access to the tools for interpretation and analysis of data to support extended, sophisticated investigations. In this respect, WorldWatcher represents a large swing of the pendulum away from the Greenhouse Effect Visualizer, which did not allow for any manipulation of its pre-rendered visualizations and provided no operations that could be performed on the underlying data. In contrast, WorldWatcher provides a broad array of options for customizing the display of visualizations, performing quantitative analyses of the data, and viewing data in other visual representations. We highlight four categories of these features in the following.

Appearances. In WorldWatcher, an appearance is a data structure that describes a visualization's displayed units, color scheme, range of displayed values, magnification, and spatial and chromatic resolution. WorldWatcher allows the user to customize the appearance of any visualization and to apply one visualization's appearance parameters to other visualizations to make them visually comparable. Appearance data structures provide the mechanism for establishing default settings for the display of specific variables, a scaffold for learners that we first used in Climate Visualizer. The range of appearance settings in WorldWatcher is comparable to those of general-purpose visualization tools used by scientists, providing learners with the same sophisticated tools for visual interpretation as scientists.

Selection regions. World Watcher provides a number of mechanisms for selecting regions within visualizations. Selection regions enable learners to identify and focus on specific areas of interest. The mechanisms for creating regions include a rectangular selection tool, a lasso for drawing region boundaries, and select-by-location (e.g., Australia or Utah) and select-by-value (e.g., between $32{ }^{\circ} \mathrm{F}$ and $72^{\circ} \mathrm{F}$ ) operations. Region masks can be combined using Boolean union, intersection, and subtraction operations; can be copied from one visualization to another; and can be stored in files. Thus regions allow users to make sophisticated queries to identify areas of the world with specific data attributes.

Mathematical and statistical analyses. WorldWatcher allows students to analyze and create data through simple statistical and mathematical operations. It provides summary statistics (max, min, and mean) both for an entire visualization and for any selected region. WorldWatcher also allows students to manipulate the data in an image by applying the basic arithmetic operations at every point in an entire image or a selected region. A second set of arithmetic operations enable students to perform binary operations on data sets, including addition, subtraction, multiplication, division, maximum, minimum, and a form of correlation. So, for example, a learner can investigate seasonal differences by subtracting January's temperature from July's. 
Alternative visual representations. To give users more leverage in tracking patterns in data over space and time, WorldWatcher provides a number of other visual representations in addition to the standard color maps including animations, histograms, line plots, and scatter plots.

\section{Background Knowledge}

The design of WorldWatcher addresses learners' needs for background knowledge through both technology and curriculum design.

The technology design expands upon the knowledge resources that were first integrated into a visualization environment in the Greenhouse Effect Visualizer. WorldWatcher includes an extensive multimedia database of explanatory materials that we call a MediaBase. The knowledge resources we have assembled cover three areas: science content, the data library, and the techniques of visualization and data analysis. The science content resources cover topics related to climate and climate change. The data library documentation describes the sources and uses of the data sets. The visualization and analysis resources provide documentation on the tools and operations available within WorldWatcher and their use in investigations. The contents of the MediaBase are accessible from within the visualization environment to enable users to access it on an as-needed basis. ${ }^{6}$

The curriculum design incorporates activities to help develop the scientific knowledge required to engage in investigations of data successfully. For example, one of the challenges exposed by the Greenhouse Effect Visualizer and its predecessors was the difficulty that students had in understanding the quantities measured by the data and their units of measurement. The LeTUS Global Warming Curriculum addresses this issue by integrating concrete, hands-on experiences with computer-based activities. For example, in their investigation of the influence of reflectivity on climate, students begin with a traditional science lab in which they place thermometers in envelopes of different colors under a light source. They track the temperature in each envelope to see the effect of reflectivity on temperature. This activity is designed to provide students with a physical experience of reflectivity on a familiar scale as preparation for a WorldWatcher activity in which they explore the reflectivity of Earth on a global scale. In this investigation, they look at the relation among ground cover, reflectivity, and temperature.

\footnotetext{
${ }^{6}$ The MediaBase was still under development at the time of writing. It currently includes documentation to assist students and teachers with the use of WorldWatcher and background information about the available data. Explanatory resources for science content are currently distributed on paper as part of the Global Warming curriculum materials.
} 


\section{Organizing and Managing Open-Ended Inquiry}

Although the Climate Visualizer included the Collaboratory Notebook as a support for managing open-ended inquiry, the simple, short-term activities students conducted with the visualizer did not require the support of the Collaboratory Notebook. However, as we returned to the goal of facilitating extended inquiry with WorldWatcher, we felt it was necessary once again to provide support for managing the process and products of short investigations. In discussions with teachers about investigations their students had conducted in the past, many complained that students would forget from day to day what they had done and what they had left to do in an activity. These experiences support the conclusions of others that learning to record and use the transient thoughts, actions, and products of the inquiry process is an important part of learning to conduct successful open-ended investigations (de Jong \& van Joolingen, 1998; Loh et al., 1997; Thornburg \& Pea, 1991). Maintaining an accurate record is necessary to support the activities of planning, monitoring, reflecting, and communicating that are critical for conducting and learning from inquiry. Unfortunately, many students do not develop the habits and skills of maintaining good records because they are not necessary to be successful at traditional school practices. To have the opportunity to master these skills, students must have tools that support them in maintaining records.

WorldWatcher incorporates support for record-keeping in the form of notebook and annotation facilities. WorldWatcher notebooks are multimedia documents that can contain formatted text, graphics, and hypermedia links to visualization data and other notebooks. Students create notebooks using a text editor that allows them to embed graphics and links. Visualization links allow users to store a visualization in a file with all of its current appearance settings. This capability allows students to save the state of their inquiry to return to it later or to allow others to recreate their investigation. The annotation capabilities allow users to associate specific notebooks with a visualization and to document visualizations using a title and brief description that displays in the visualization window. To assist students in the tracking process, WorldWatcher automatically annotates visualizations that are created through mathematical operations with a documentation string that describes the source data and the operation that was used in the creation of that visualization. In a related research effort, we have developed a separate application called the Progress Portfolio (Loh et al., 1997), which provides even greater support for organizing, annotating, and communicating about the products of the inquiry process. The Progress Portfolio was designed to be used in conjunction with any investigation environment. It includes a "Data Camera" that allows learners to store and annotate images from an application like WorldWatcher in the Progress Portfolio without disrupting the flow of their work by requiring them 
to switch from one program to another. Because the Progress Portfolio has only recently been released, we do not yet have any experience with students using it and WorldWatcher together.

\section{Practical Constraints}

Like the Radiation-Budget Visualizer, WorldWatcher avoided the network performance issues that were an obstacle to use of both the Climate Visualizer and the Greenhouse Effect Visualizer in classrooms. Because its data sets are available on a CD-ROM, it does not place extraordinary demands on storage either. Finally, although it places demands on computational power that are similar to its predecessors, the steady advance in technology has reduced that challenge. The least expensive Macintosh computers that have been on the market since 1996 all provide the computational power that WorldWatcher requires.

\section{Issues Raised by Classroom Experiences}

WorldWatcher has been used in a wide range of classrooms from middle school through college. ${ }^{7}$ Although little formal evaluation has been conducted on those uses, our observations and reports do not reveal issues of the magnitude of those raised by their predecessors for motivation, accessibility, background knowledge, management of inquiry, or meeting the practical constraints of classrooms. Where prior visualizers raised issues that were clear obstacles for the use of all or most students in the classes we observed or were in contact with, the concerns that are being raised by the use of WorldWatcher seem to be less severe or to affect specific populations of students. Because of the progress made through the intensive design process leading to WorldWatcher, identifying the next set of issues will require a more careful evaluation process than was required by the previous environments. We provide a brief overview of these evaluation efforts in the next steps described in the final section of this article. Here, we present a brief summary of WorldWatcher's status with respect to the specific challenges of inquiry-based learning.

\footnotetext{
${ }^{7}$ It has been difficult to track the actual use of WorldWatcher in classrooms. Several thousand copies of WorldWatcher have been distributed over the Internet and on CD-ROM, many of those directly to teachers. However, we have no data on how many of those copies were actually used in classrooms. The most conservative estimate from the schools participating in the CoVis Project and other schools in direct contact with our research group is that at least 50 of those teachers have used WorldWatcher in their classrooms.
} 
Motivation. The newest Global Warming Curriculum has demonstrated promise in providing a coherent motivating context in pilot tests in three schools. However, we have observed difficulties with students losing sight of the overall context as they become involved in individual activities. The problem appears when they complete an activity and have lost track of why they conducted the activity and where they are going next. Reestablishing that motivating context is an important challenge, and we are making revisions to the curriculum in response.

Accessibility of investigation techniques. Evidence from dozens of classrooms and several workshop-setting studies shows that despite a number of minor usability problems with WorldWatcher's user-interface, students at a wide range of age and ability levels are able to master the major visualization and data analysis operations in WorldWatcher within their first 45-min session. We have observed all of the operations in WorldWatcher appropriated successfully by middle and high schools students for use in student-directed investigations. ${ }^{8}$ Nevertheless, we do not see uniform appropriation of features across student populations, nor do students always use them in a careful, scientific fashion. We have been especially struck by the strength of the confirmation bias in student investigations. Understanding the factors that contribute to these observations will require more careful attention to individual differences in future research.

Background knowledge. We have received favorable responses from teachers to the knowledge resources in WorldWatcher and the activities designed to give concrete experience with the quantities measured by the data. However, we are still awaiting evidence of their value from direct observation of students.

Organizing and managing open-ended inquiry. Teachers also respond favorably to the WorldWatcher notebook facility, and we have observed students using it successfully to record their work when asked to in guided activities. We do not yet have a significant body of experience with students engaged in open-ended activities to learn if and how students use it spontaneously. Our early impression is that the technological support in the form of notebooks is only part of the solution and that helping students to recognize the value of record-keeping and develop effective record-keeping habits is going to require additional supports, such as providing structures for students to work within and prompts for metacognition (Linn et al., in press; Scardamalia et al., 1989; Tabak et al., 1996).

\footnotetext{
${ }^{8}$ This excludes histograms and scatter plots, which were added specifically for use at the undergraduate level.
} 
Practical constraints of the learning context. The biggest current practical challenge to WorldWatcher's compatibility with typical learning contexts is its restriction to the Apple Macintosh. This issue is being addressed through further software development. In addition, although the activities in the Global Warming Curriculum have been carefully designed to accommodate the restrictions of 45-min class periods, teachers have raised concerns about the total amount of time the entire curriculum takes and balancing it against other curricular needs. This raises the issue of trade-offs between breadth and depth of coverage that are common in the implementation of inquiry-based learning.

\section{LESSONS LEARNED: A DESIGN FRAMEWORK FOR TSIL}

The most important lesson of the experiences reported here is that the implementation of TSIL requires an integrated process of both technology and activity design. In particular, these experiences show that to address the challenges of inquiry-based learning successfully, the TSIL design process must coordinate four interdependent components: the identification of a motivational context, the selection and sequencing of activities, the design of investigation tools, and the creation of process supports. By exposing a wide range of challenges to inquiry-based learning, the design effort described here provides the opportunity to explore strategies for each of these four components. In this section, we use these four components as a framework to organize our discussion of the strategies we identified and the ways those strategies address the challenges of inquiry-based learning.

\section{Identification of a Motivational Context}

To address the need for motivation, designers of inquiry-based learning must identify a motivating context for inquiry early in the design process. Our early experiences with the Climate Visualizer demonstrated the risks of not establishing a meaningful motivating context. In addition, we found ourselves in a position where we could not retrofit a motivating context to the existing design. Because the motivational context has critical implications for the other elements of a TSIL design, it must be identified early in the design process. In the process described here, for example, the selection of global warming as a motivating context influenced the nature and sequencing of the investigation activities and determined the contents of the data libraries and the knowledge resources.

Our strategy for the selection of a motivating context resembles those of other researchers in inquiry and project-based science learning in its focus on a meaningful, controversial, and open scientific issue (e.g., Barron et al., 1998; 
Blumenfeld et al., 1991). Through our conversations with students and teachers, we identified four elements that give the investigation of global warming the interest and value that are necessary to initiate engagement. First, the topic is familiar. Unlike many of the topics that students study in traditional science curricula, global warming is an issue that they have heard about. Second, it has potential direct implications for students. They are concerned that they may experience the effects of global warming. Third, the possibility of global warming and the measures that have been suggested to reduce it have important social and policy implications that draw on students' senses of fairness and entitlement. Fourth, the scientific issues associated with global warming are a matter of legitimate uncertainty and controversy in the scientific community. Students are intrigued by the fact that scientists do not understand the science of climate completely and that they even disagree. In comparison to the settled science that they are used to learning about in school, students find the open controversy appealing. These four properties of global warming apply to many issues in science and can serve as guidelines for the design of inquiry learning in general. However, they do not by any means constitute a complete list of features of a motivating context, and as Blumenfeld et al. (1991) point out, there is a frustrating lack of empirical data describing the interests of learners that could be drawn on in the design of inquiry-based learning.

The selection of global warming as a motivating context had important implications for the other technology and curriculum design elements. For example, we developed an increasingly comprehensive library of data sets that supported investigations of global warming and its potential causes and implications. We also developed and refined curricula designed to establish global warming as a compelling issue for learners and then draw on their concern over global warming to motivate investigations of the science of global climate and climate change.

\section{Selection and Sequencing of Activities}

The selection and sequencing of activities provides an opportunity to address the challenges of motivation, accessibility, and background knowledge. In this process, we used staging and bridging activities to address these three challenges.

Having selected global warming as the motivational context, we were able to create sequences of staging activities that developed motivation by exposing students to the potential implications of global warming through discussions, readings, and videos. These activities were designed to simultaneously develop interest and raise the key scientific questions that students would investigate over the course of the unit. The sequencing of staging activities in this way can help to establish long-term motivation by connecting students' concerns and interests to specific scientific questions. Within this larger context, we also used the bridging activity of map drawing to elicit curiosity about specific issues. By asking students 
to articulate their prior conceptions, these types of activities can help to establish a focused interest in specific phenomena.

We also addressed an important challenge of accessibility through the selection and sequencing of activities. This was the challenge of helping students to understand the opportunities offered by the available investigation techniques. Beginning with the Radiation-Budget Visualizer, we addressed this challenge by creating sequences of structured investigations that introduced the capabilities of the investigation tools in manageable chunks and demonstrated their usefulness for answering questions within the motivating context. By guiding students through short, well-structured investigations, staging activities can provide students with conceptual models of investigation techniques that the students can draw on in subsequent open-ended investigations. The development of these conceptual models helps to make the investigation techniques more accessible.

The design of staging and bridging activities also enabled us to address the challenge of background knowledge. Each of the staging activities in the curriculum sequences described here was designed to help students develop and refine their understanding of specific content. Sequenced appropriately, staging activities can build on each other in successive steps to help students develop the knowledge and skills that will enable them to engage in open-ended investigations.

\section{Design of Investigation Tools}

The design of a scientific investigation tool is the process of selecting specific operations and creating user-interfaces to them. In the case of the visualization environments described here, the design of the investigation tools also included the assembly of data libraries. In this work we found that the design of investigation tools could play an important role in addressing the challenges of motivation, accessibility, and practical constraints.

In the design process reported here, we addressed motivation through the selection of data sets and through the design of operations to support bridging activities. The selection of data sets enabled us to draw on the motivating context of global warming. The visualizers prior to WorldWatcher had difficulty initiating and maintaining engagement because of the limitations of their data libraries. The data library in the Climate Visualizer was unable to initiate engagement because its limited data did not support investigations that students found interesting. In the design of the subsequent Radiation-Budget and Greenhouse Effect Visualizers, the selection of data sets related to Earth's energy balance enabled us to draw on global warming as a motivating context. However, it wasn't until the development of WorldWatcher, when we added data addressing human contributions to possible global warming and the potential implications of global climate change, that we were able to effectively initiate and maintain engagement for large numbers of 
students. The design of operations also enabled us to address the challenge of motivation, specifically through the creation of operations to supporting bridging activities. As we described previously, the bridging activities in which students draw visualizations to articulate their initial conceptions can help to create interest. To support these bridging activities, we designed a number of operations, modeled on the interfaces of graphics programs, to enable students to create new WorldWatcher data sets by "painting" them.

From our first designs, we recognized the need to address accessibility through the design of investigation tools. Following the Learner-Centered Design approach, we began by creating scaffolds in the tools. We identified tacit knowledge that scientists draw on in the creation and interpretation of visualizations and embedded that knowledge in the form of contextual information in the user-interface. We maintained this approach throughout the design history. We provided additional scaffolds in the form of default settings that enabled learners to create interpretable visualizations without requiring any foreknowledge of the data. Finally, in we created operations and representations that were specifically designed to make the properties of the tools clear to learners. These included the spreadsheet-like display of numerical values in magnified visualizations (Figure 9) and the ability to project rectangular visualizations into alternative projections, including cut-and-fold images that can be printed and assembled into a polyhedral globe (Figure 10). All of these strategies address the problem that learners lack the background knowledge that scientists bring to their use of scientific investigation tools. The supports in the software made investigation techniques accessible to learners by embedding that knowledge in the interface for learners to draw on, by bypassing the need for that knowledge, or by helping the learners to develop the knowledge themselves.

The two practical constraints of the learning environment that we continually confronted were limits on available time and technology infrastructure in classrooms. Although these issues draw designers' attention away from the fundamental processes of teaching and learning, they are nevertheless critical concerns for the implementation of any approach to learning. In this design process, we were repeatedly confronted by the need to improve the performance of the software and match its requirements to the technology infrastructure in schools. The rapidly changing nature of technology means that the specific strategies we employed in this process have little general value. However, these experiences do demonstrate the critical importance of both speed and reliability for classroom technologies.

\section{Creation of Process Supports}

Process supports are the elements of a TSIL design that address the needs of inquiry-based learning beyond the direct support for the investigation techniques. In 
the case of the designs described here, the process supports that proved necessary were knowledge resources and record-keeping tools. These supports address the challenges of background knowledge and managing extended activities.

In this design history, we addressed the need for background knowledge in the Greenhouse Effect Visualizer and in by creating information resources within the software environments. These resources provided a mechanism for learners to access background information as the need arose in the course of an investigation. By providing these resources, we attempted to reduce the demand on the teacher and existing classroom resources, thereby simultaneously addressing practical constraints of the learning environment. By placing these resources within the software environment, we took advantage of the opportunity to link them directly to data or activities, making it possible for students to move between investigation activities and knowledge resources with minimal interruption.

We addressed the need to support students in organizing and managing inquiry activities by providing them with tools to record the process and the intermediate products of their investigations. Record-keeping tools provided students with the opportunity to create and monitor plans, articulate hypotheses, analyze evidence carefully, and reflect on their progress. Our experiences indicate that these record-keeping facilities were helpful but that they were not sufficient to resolve the challenges of managing extended activities.

\section{Putting the Elements Together}

Each of the elements of the TSIL design process can address different facets of the challenges of implementing inquiry-based learning. Assembled into a coherent whole, they have the potential to successfully achieve all three of the categories of learning objectives for inquiry-based learning that we presented earlier-specific inquiry skills, general inquiry abilities, and scientific content. By addressing the challenge of motivation, an effective TSIL design can create sufficient engagement to bring about learning. By making investigation techniques accessible, a design can engage students in inquiry activities through which they achieve mastery of specific inquiry skills and can develop new content understanding through discovery and refinement. Once engaged in inquiry, students often require additional knowledge to complete their investigations and interpret their results. In successfully addressing the challenge of background knowledge, a design can meet this need by supporting the further development of content understanding. By addressing the challenge of supporting extended, open-ended activities, a design can provide the opportunity to fulfill the motivating context and allow learners to develop general inquiry abilities. Finally, addressing the practical constraints of the learning context makes it possible for such a design to achieve these learning objectives in realistic settings. We do not claim to have fully achieved these objectives 
through the designs presented here. However, the strategies we employed in these designs have been successful at reducing the obstacles to implementing inquiry-based learning, bringing the designs substantially closer to achieving those objectives.

\section{NEXT STEPS}

WorldWatcher and its accompanying curricula are the products of an extensive iterative design process. The advances made in the design of WorldWatcher and the Global Warming Curriculum provide the opportunity to pursue new research directions. In the next stage of this research, we are initiating a new phase of evaluation, and we are broadening our design scope to include support for the role of the teacher.

\section{Evaluation}

The issues for inquiry-based learning discussed here were identified through an iterative design and evaluation process. This formative evaluation has focused on the identification and resolution of critical obstacles to the implementation of effective inquiry-based learning with scientific visualization. However, the success of WorldWatcher and its accompanying curricula in addressing many of the challenges raised by its predecessors represents an important transition in this design research process. Having reached this point, we are currently initiating a more formal evaluation process designed to take advantage of WorldWatcher and its accompanying curricula to explore the theories and assumptions that have guided this design process. The goal of this next phase of evaluation will be to create a rich description of the enactment of TSIL in classrooms, with attention to the variation across and within classrooms, and to use these descriptions to help us understand the contributions of the design strategies discussed here to the implementation of TSIL in classrooms and to attitudinal and learning outcomes.

\section{Design for Teachers}

In the discussion of the design process in this article, we have focused primarily on the needs of learners. However, over the course of this effort, we have become increasingly aware of the challenges that TSIL poses for teachers. For example, at many points in this design process, we were told by individual teachers that they could not use our software or curriculum because they did not feel comfortable enough with the technology, the content, or the process of man- 
aging TSIL. Our experiences have convinced us that supporting the role of the teacher raises important additional challenges for the design of both software and activities beyond the issues for students that we have discussed here. We have begun to explore these issues through a new program of design research focusing on support for the enactment of inquiry-based science learning by teachers (Brown \& Edelson, 1998). In this new research, we are investigating the issues that confront teachers in the enactment of curricula like the Global Warming Curriculum and how to prepare materials for teachers that will support them in planning, customizing, conducting, and assessing them within the practical constraints of their local environment.

\section{ACKNOWLEDGMENTS}

This work has been supported in part by the National Science Foundation under the Grants MDR-9253462, RED-9453715, RED-9454729, ESI-9720687, and REC-9720383. Additional support was provided by Apple Computer, Sun Microsystems, and Spyglass, Inc.

We would like to acknowledge the crucial contributions of all of the researchers and participating teachers and students in the and SSciVEE Projects to the designs described here, as well as to the development and refinement of the ideas in this article. We are also grateful to our reviewers and to Janet Kolodner for helpful comments.

Important contributions to the development of the software and curriculum discussed in this article were made by Joseph Polman, Kevin O'Neill, Barry Fishman, Laura D'Amico, Steven McGee, Joey Gray, Paul Forward, Patricia Carlson, Eileen Lento, Matthew Brown, Duane Griffin, and Louis Gomez. WorldWatcher was written by Brian Clark. Ray Pierrehumbert, David Hollander, and Brad Sageman served as consultants on scientific content and practice.

\section{REFERENCES}

American Association for the Advancement of Science. (1994). Benchmarks for science literacy. New York: Oxford University Press.

Asbell-Clarke, J., \& Barclay, T. (1996). Discovering the scientist within: Hands-On Universe. In Hands-On! (Vol. 19, pp. 4-5, 17). Cambridge, MA: TERC.

Barron, B. J. S., Schwartz, D. L., Vye, N. J., Petrosino, A., Zech, L., Bransford, J. D., \& The Cognition and Technology Group at Vanderbilt. (1998). Doing with understanding: Lessons from research on problem- and project-based learning. The Journal of the Learning Sciences, 7, 271-311.

Barstow, D., \& Berenfeld, B. (1996, April). Data visualization as an essential component of telecollaborative inquiry-based science learning. Paper presented at the annual meeting of the American Education Research Association, New York.

Berlyne, D. E. (1966). Curiosity and exploration. Science, 153, 25-33. 
Blumenfeld, P. C., Soloway, E., Marx, R., Krajcik, J. S., Guzdial, M., \& Palincsar, A. (1991). Motivating project-based learning: Sustaining the doing, supporting the learning. Educational Psychologist, 26, 369-398.

Brown, M., \& Edelson, D. C. (1998). Software in context: Designing for students, teachers, and classroom enactment. In A. S. Bruckman, M. Guzdial, J. L. Kolodner, \& A. Ram (Eds.), Proceedings of ICLS 98: International Conference on the Learning Sciences, Atlanta, GA (pp. 63-69). Charlottesville, VA: AACE.

Bruner, J. S. (1961). The act of discovery. Harvard Education Review, 31, 21-32.

D'Amico, L., Fishman, B., Gordin, D. N., McGee, S., O'Neill, D. K., \& Polman, J. (1994). The atmospheric sciences: Six views into a community of practice. Unpublished manuscript, Northwestern University.

de Jong, T., \& van Joolingen, W. R. (1998). Scientific discovery learning with computer simulations of conceptual domains. Review of Educational Research, 68, 179-201

Dewey, J. (1964a). Progressive organization of subject matter. In R. D. Archambault (Ed.), John Dewey on education: Selected writings (pp. 373-387). Chicago: University of Chicago Press.

Dewey, J. (1964b). Science as subject matter and as method. In R. D. Archambault (Ed.), John Dewey on education: Selected writings (pp. 182-195). Chicago: University of Chicago Press.

Edelson, D. C. (1998a). Matching the design of activities to the affordances of software to support inquiry-based learning. In A. S. Bruckman, M. Guzdial, J. L. Kolodner, \& A. Ram (Eds.), Proceedings of ICLS 98: International Conference on the Learning Sciences, Atlanta, GA, December 16-19 (pp. 77-83). Charlottesville, VA: AACE.

Edelson, D. C. (1998b). Realising authentic science learning through the adaptation of science practice. In B. J. Fraser \& K. Tobin (Eds.), International Handbook of Science Education (pp. 317-331). Dordrecht, The Netherlands: Kluwer.

Edelson, D. C., Pea, R. D., \& Gomez, L. M. (1996a). The collaboratory notebook: Support for collaborative inquiry. Communications of the ACM, 39, 32-33.

Edelson, D. C., Pea, R. D., \& Gomez, L. (1996b). Constructivism in the collaboratory. In B. Wilson (Ed.), Constructivist learning environments: Case studies in instructional design. Englewood Cliffs, NJ: Educational Technology Publications.

Eisenberg, M., \& Nishioka, A. (1997). Creating polyhedral models by computer. Journal of Computers in Mathematics and Science Teaching, 16, 477-511.

Ferguson, W., Bareiss, R., Birnbaum, L., \& Osgood, R. (1992). ASK systems: An approach to the realization of story-based teachers. The Journal of the Learning Sciences, 2, 95-134.

Fishman, B., \& D'Amico, L. (1994). Which way will the wind blow? Networked tools for studying the weather. In T. Ottmann \& I. Tomek (Eds.), Educational Multimedia and Hypermedia, 1994 (pp. 209-216). Vancouver, BC: Association for the Advancement of Computing in Education.

Frodeman, R. (1995). Geological reasoning: Geology as interpretive and historical science. GSA Bulletin, 107, 960-968.

Gomez, L. M., Gordin, D. N., \& Carlson, P. (1995). A case study of open-ended scientific inquiry in a technology supported classroom. In J. Greer (Ed.), Proceedings of AI-Ed '95, Seventh World Conference on Artificial Intelligence in Education (pp. 17-24). Charlottesville, VA: Association for the Advancement of Computing in Education.

Gordin, D. N., Edelson, D. C., \& Pea, R. D. (1995, January). The Greenhouse Effect Visualizer: A tool for the science classroom. Preprints of the Fourth American Meteorological Society Education Symposium, Dallas, Texas (J47-J56).

Gordin, D. N., \& Pea, R. D. (1995). Prospects for scientific visualization as an educational technology. The Journal of the Learning Sciences, 4, 249-279.

Gordin, D. N., Polman, J. L., \& Pea, R. D. (1994). The Climate Visualizer: Sense-making through scientific visualization. Journal of Science Education and Technology, 3, 203-226. 
Greenberg, R., Kolvoord, R. A., Magisos, M., Strom, R. G., \& Croft, S. (1993). Image processing for teaching. Journal of Science Education and Technology, 2, 469-480.

Greeno, J., Collins, A., \& Resnick, L. B. (1996). Cognition and learning. In R. Calfee \& D. Berliner (Eds.), Handbook of educational psychology. New York: Macmillan.

Guzdial, M., Turns, J., Rappin, N., \& Carlson, D. (1995). Collaborative support for learning in complex domains. In J. L. Schnase \& E. L. Cunnius (Eds.), Proceedings of CSCL 95: Computer Support for Collaborative Learning (pp. 157-160). Mahwah, NJ: Lawrence Erlbaum Associates, Inc.

Hancock, C., Kaput, J. J., \& Goldsmith, L. T. (1992). Authentic inquiry with data: Critical barriers to classroom implementation. Educational Psychologist, 27, 337-364.

Hawkins, J., \& Pea, R. D. (1987). Tools for bridging the cultures of everyday and scientific thinking. Journal of Research in Science Teaching, 24, 291-307.

Hiebent, J., Carpenter, T. P., Fennema, E., Fuson, K., Human, P., Murray, H., Olivier, A., \& Wearne, D. (1996). Problem solving as a basis for reform in curriculum and instruction: The case of mathematics, Educational Researcher, 25(4), 12-21.

Hoadley, C. M., Hsi, S., \& Berman, B. P. (1995). The Multimedia Forum Kiosk and SpeakEasy. Proceedings of ACM Multimedia ' 95 (pp. 363-364). New York: ACM Press.

Hunt, E., \& Minstrell, J. (1994). A cognitive approach to the teaching of physics. In K. McGilly (Ed.), Classroom lessons: Integrating cognitive theory and classroom practice (pp. 51-74). Cambridge, MA: MIT Press.

Ireton, M. F. W., Manduca, C. A., \& Mogck, D. W. (Eds.). (1996). Shaping the future of undergraduate earth science education: Innovation and change using an earth system approach. Washington, DC: National Science Foundation.

Jackson, S. L., Stratford, S. J., Krajcik, J., \& Soloway, E. (1996). A learner-centered tool for students building models. Communication of the ACM, 39(4), 48-49.

Kaufmann, W., \& Smarr, L. L. (1993). Supercomputing and the transformation of science. New York: Freeman.

Krajcik, J., Blumenfeld, P. C., Marx, R. W., Bass, K. M., Fredericks, J., \& Soloway, E. (1998). Inquiry in project-based science classrooms: Initial attempts by middle school students. The Journal of the Learning Sciences, 7, 313-350.

Linn, M. C., Bell, P., \& Hsi, S. (1998). Lifelong science leaming on the Internet: The knowledge integration environment. Interactive Learning Environments, 6(1-2), 4-38.

Linn, M. C., diSessa, A., Pea, R. D., \& Songer, N. B. (1994). Can research on science learning and instruction inform standards for science education? Journal of Science Education and Technology, $3(1), 7-15$.

Linn, M. C., Songer, N. B., \& Eylon, B. S. (1996). Shifts and convergences in science learning and instruction. In R. Calfee and D. Berliner (Eds.), Handbook of educational psychology. New York: Macmillan.

Loh, B., Radinsky, J., Reiser, B. J., Gomez, L. M., Edelson, D. C., \& Russell, E. (1997, December). The progress portfolio: Promoting reflective inquiry in complex investigation environments. Proceedings of CSCL 97: Computer Support for Collaborative Learning, Toronto, Canada (pp. 169-178).

Mandinach, E. B., \& Cline, H. F. (1996). Classroom dynamics: The impact of a technology-based curriculum innovation on teaching and learning. Journal of Educational Computing Research, 14(1), 83-102.

McCormick, B. H., DeFanti, T. A., \& Brown, M. D. (Eds.). (1987, November). Special issue on visualization in scientific computing. Computer Graphics, $2 I(6)$.

National Aeronautics and Space Administration. (1998). Understanding our changing planet: Earth Science Enterprise 1998 applications fact book. Washington, DC: Author.

National Aeronautics and Space Administration Advisory Council. (1988). Earth system science: $A$ closer view (Report of the Earth System Sciences Committee, NASA Advisory Council). Washington, DC: National Aeronautics and Space Administration. 
National Research Council. (1996). National science education standards. Washington, DC: National Academy Press.

O'Neill, D. K., \& Gomez, L. (1994). The collaboratory notebook: A distributed knowledge-building environment for project-enhanced learning. In T. Ottmann \& I. Tomek (Eds.), Educational Multimedia and Hypermedia, 1994: Proceedings of Ed-Media 94 (pp. 416-423). Charlottesville, VA: Association for the Advancement of Computers in Education.

Pea, R. D. (1993, May). Distributed multimedia learning environments: The collaborative visualization project. Communication of the $A C M, 36(5), 60-63$.

Penner, D. E., Giles, N. D., Lehrer, R., \& Schauble, L. (1997). Building functional models: Designing an elbow. Journal of Research in Science Teaching, 34, 125-143.

Plutchak, J., Hall, S., Wojtowicz, D., Sridhar, M., Ramamurthy, M., \& Wilhelmson, R. (1998). Weather World 2010: A customizable, user-oriented WWW site. Proceedings of the 14th International Conference on Interactive Information and Processing Systems (IIPS) for Meteorology, Oceanography, and Hydrology, Phoenix, Arizona (pp. 402-403).

Resnick, M. (1994). Turtles, termites, and trafficjams: Explorations in massively parallel microworlds. Cambridge, MA: MIT Press.

Rock, B. N., Blackwell, T. R., Miller, D., \& Hardison, A. (1997). The GLOBE program: A model for international environmental education. In K. C. Cohen (Ed.), Internet links for science education: Student-Scientist partnerships. New York: Plenum.

Samson, P. J., Steremberg, A., Ferguson, J., Kamprath, M., Masters, J., Monan, M., \& Mullen, T. (1994, January). Blue-Skies: A new interactive teaching tool for K-12 education. Proceedings of the Third American Meteorological Society Education Symposium (pp. J9-J14).

Scardamalia, M., \& Bereiter, C. (1994). Computer support for knowledge-building communities. The Journal of the Learning Sciences, 3, 265-283.

Scardamalia, M., Bereiter, C., McLean, R. S., Swallow, J., \& Woodruff, E. (1989). Computer-supported intentional learning environments. Journal of Educational Computing Research, 5(1), 51-68.

Schank, R. C. (1999). Dynamic memory revisited. New York: Cambridge University Press.

Schank, R. C., Fano, A., Bell, B., \& Jona, M. (1993/1994). The design of goal-based scenarios. The Journal of the Learning Sciences, 3, 305-346.

Schauble, L., Glaser, R., Duschl, R. A., Schulze, S., \& John, J. (1995). Students' understanding of the objectives and procedures of experimentation in the science classroom. The Journal of the Learning Sciences, 4, 131-166.

Soloway, E., Guzdial, M., \& Hay, K. E. (1994). Learner-centered design: The challenge for HCI in the 21 st century. Interactions, $1,36-47$.

Songer, N. B. (1995). Knowledge construction through exchange and dialogue: A case study of Kids as Global Scientists. The Journal of the Learning Sciences, 5(4), 297-328.

Tabak, I., Smith, B. K., Sandoval, W. A., \& Reiser, B. J. (1996, June). Combining general and domain-specific strategic support for biological inquiry. In C. Frasson, G. Gauthier, \& A. Lesgold (Eds.), Proceedings of the Third International Conference on Intelligent Tutoring Systems (ITS '96), Montreal (pp. 288-296). New York: Springer-Verlag.

Thornburg, D. G., \& Pea, R. D. (1991). Synthesizing instructional technologies and educational culture: Exploring cognition and metacognition in the social studies. Journal of Educational Computing Research, $7(2), 121-164$.

Wallace, R., Bos, N., Hoffman, J., Hunter, H. E., Kiskis, D., Klann, E., Krajcik, J., Peters, G., Richardson, D., Ronen, O., \& Soloway, E. (1998). ARTEMIS: Learner-centered design of an information seeking environment for $\mathrm{K} 12$ education.

Wallace, R., Soloway, E., Krajcik, J., Bos, N., Hoffman, J., Hunter, H., Kiskis, D., Klann, E., Peters, G., Richardson, D., \& Ronen, O. (1998, April). ARTEMIS: Learner-centered design of an information seeking environment for $\mathrm{K}-12$ education. Conference Proceedings of CHI98: Human Factors in Computing Systems, Los Angeles, California (pp. 195-202). New York: ACM. 


\section{EDELSON, GORDIN, PEA}

Welch, W. W., KJopfer, L. E., Aikenhead, G. S., \& Robinson, J. T. (1981). The role of inquiry in science education: Analysis and recommendations. Science Education, 65, 33-50.

White, B. Y. (1993). ThinkerTools: Causal models, conceptual change, and science education. Cognition and Instruction, 10, 1-100.

Wilensky, U., \& Resnick, M. (1999). Thinking in levels: A dynamic systems approach to making sense of the world. Journal of Science Education and Technology, 8(1), 3-19. 